\title{
“MADRID, NUEVO NORTE", UN PROYECTO CONTRA LA COVID-19: EL TURISMO COMO OPORTUNIDAD
}

\author{
Ignacio Sotelo Pérez* \\ Instituto Universitario de Ciencias Ambientales. Universidad Complutense de Madrid \\ http://orcid.org/0000-0003-0619-7732 \\ María Sotelo Pérez** \\ Universidad Rey Juan Carlos. Madrid. \\ https://orcid.org/0000-0002-5541-7941 \\ José Antonio Sotelo Navalpotro*** \\ Instituto Universitario de Ciencias Ambientales. Universidad Complutense de Madrid \\ https://orcid.org/0000-0003-2800-6677
}

\section{RESUMEN}

La historia urbanística que ha dado paso al denominado como "Madrid, Nuevo Norte" comienza a finales del siglo pasado, cuando se estudia programar para la estación de Chamartín y sus alrededores, una remodelación exhaustiva. Finalmente, este planteamiento, no consiguió que tuviera el suficiente reconocimiento institucional para que se llevara a cabo un plan urbanístico que resolviera la situación en la que se encontraba unos terrenos, y en unos suelos que comprendían la conocida como "Área de Planeamiento Específico (APE 08.03), Prolongación de la Castellana" (hoy "Madrid, Nuevo Norte"). A lo largo del presente estudio nos aproximamos, tal y como podemos comprobar en las variables integrantes de la Metodología desarrollada, los espacios residuales que forman parte de los Lost spaces, que predominan en este espacio geográfico. Punto de partida de ulteriores investigaciones en las que la referencia deben ser las actividades turísticas que se generarán en la que podríamos denominar etapa posterior a la "Covid-19".

Fecha de recepción: 25 de mayo de 2020

Fecha de aceptación: 19 de octubre de 2020

1 La presente investigación se enmarca en el proyecto de investigación SANTANDER-UCM (2018). PR75/18-21573.

* Investigador F.P.U. (Formación del Profesorado Universitario). Instituto Universitario de Ciencias Ambientales. Universidad Complutense de Madrid. C/ Manuel Bartolomé Cossío, s/n. Ciudad Universitaria. 28040 MADRID (España). E-mail: ignaciosoteloperez@ucm.es

** Área de Geografía Humana. Facultad de Ciencias Jurídicas y Sociales. Universidad Rey Juan Carlos. Paseo Artilleros, s/n. 28032 MADRID (España).E-mail: maria.sotelo.perez@urjc.es

*** Instituto Universitario de Ciencias Ambientales. Universidad Complutense de Madrid. C/ Manuel Bartolomé Cossío, s/n. Ciudad Universitaria. 28040 MADRID (España).E-mail: jasotelo@ucm.es 
Palabras clave: "Madrid; Nuevo Norte"; "Operación Chamartín”; Actividades Turísticas; Covid-19.

“Madrid, Nuevo Norte”, a Project against Covid-19: Tourism as an opportunity

\begin{abstract}
The urban history that has given way to the so-called "Madrid, New North" begins at the end of the last century when around the nineties, a comprehensive remodeling that completely transforms its appearance is being studied for the Madrid Chamartín station and its surroundings. Finally, this approach did not achieve, for various reasons, that it had sufficient institutional recognition for an urban plan to be carried out to resolve the situation in which there was some land that occupied about three million square meters, and on soils that comprised the so-called "Specific Planning Area (APE 08.03), Castellana Extension"; and whose operation to be more exact would be commonly known as "Operation Chamartín"; which later would be renamed with the name that currently remains of "Madrid, Nuevo Norte". Throughout this study we approach As we can see in the variables that make up the Methodology developed and applied, the residual spaces that are part of the Lost spaces (formless and useless anti spaces) predominate in this geographic space. It is a no-man's-land along the edges of the highways, whose conservation nobody cares about, and which nobody uses. Starting point for further research in which the reference should be the tourist activities that will be generated in what we could call the postCovid-19 stage.
\end{abstract}

Keywords: "Madrid; Nuevo Norte”; "Operación Chamartín”; Tourist Activities; Covid-19.

\title{
1. PRIMERA APROXIMACIÓN
}

Antes de la llegada del verano del 2020, la pandemia Covid-19, en países como España había provocado una mortalidad que superaba, en cifras oficiales, los veintisiete mil muertos; en los prolegómenos del otoño, esa cifra supera los treinta y dos mil fallecidos (en Madrid, más de nueve mil fallecidos), con un total de ochocientos mil casos de coronavirus diagnosticados. Tras varios meses de confinamiento, las consecuencias sobre la economía en general, y sobre el sector turístico en particular, son catastróficas. Ya en el mes de marzo la llegada de turistas extranjeros a España cayó en un sesenta y cinco por ciento, aproximándose tan sólo al millón y medio los turistas extranjeros que llegaron a nuestro país, en el primer trimestre el año (INE), generando verdaderos estragos en la Comunidad de Madrid, rompiéndose una serie histórica que suponía un verdadero récord de llegadas de turistas extranjeros a la región, desde hace un lustro. Invertir esta tendencia es, en la actualidad, un verdadero reto de consecuencias locales y regionales. Desde esta perspectiva, mirar hacia el futuro nos aproxima a una realidad que pasa por diversos proyectos urbanísticos, entre los que el denominado "Madrid Nuevo Norte", presenta una realidad diacrónica que cobra nuevos enfoques al aunar, consecuencias de la Covid-19, realidad urbanística y actividades turísticas, en Madrid, y en España. 
En Madrid, como en el resto de las ciudades españolas, el crecimiento urbano está configurado por la localización de las viviendas; éstas no sólo constituyen, como suelo residencial, el principal componente de la ocupación de suelo en el proceso de crecimiento urbano, sino que su papel preponderante está reforzado por el protagonismo cobrado en las últimas décadas, por la edificación masiva, y su papel en el propio crecimiento de la ciudad (de hecho, el sector inmobiliario ha cobrado una importancia calificable de excepcional, en su sistema económico de desarrolla "tardío", unido al acelerado crecimiento urbano que se ha producido en ciudades como Madrid). Todo ello acompañado de los problemas inherentes a la necesidad de vivienda en un modelo de crecimiento económico que provocó y genera una importantísima y creciente concentración demográfica en ciudades como Madrid.

No podemos olvidarnos, por otra parte, que el crecimiento urbano de nuestra ciudad está directamente unido a los mecanismos que operan en el sector inmobiliario, generando procesos consecuencia de su actuación. De hecho, cuando las condiciones de rentabilidad del mercado no son las esperadas por el sector inmobiliario, no se producirán las inversiones necesarias, y el crecimiento urbano o no se producirá o se generará a través de otros mecanismos (bien por la acción de los poderes públicos, cuando éstos asumen directamente la edificación de la ciudad y de sus áreas de influencia, bien mediante procesos de urbanización que de forma genérica podríamos calificar de urbanización marginal).

\section{LA CONSOLIDACIÓN DEL MODELO DE PRODUCCIÓN CAPITALISTA, EN EL ÁMBITO TURÍSTICO DE MADRID}

En la actualidad en Madrid no solo se ha consolidado el modelo de producción capitalista, completamente dominante, sino que ha ido acompañado de la aparición y consolidación de un sector de corte monopolista (aunque persistan aún dentro del mismo las pequeñas empresas, no como algo marginal, sino como algo funcional a la estructura del conjunto). Esto supone la posición de dominación de una capa social surgida del capital financiero, y estrechamente vinculada al mismo. De hecho, la transformación del sector no puede interpretarse, únicamente, a través de la evolución del mercado, pues ha requerido la puesta en marcha de otros mecanismos exógenos a la dinámica interna de aquel, desempeñando un papel fundamental los poderes públicos (en nuestro caso concreto, la Comunidad y el Ayuntamiento de Madrid, entre otros). Éstos no se han limitado a intervenir directamente en la producción de viviendas, sino que a través de las políticas económicas, por una parte, y la de vivienda y planeamiento, por otra, han generado un proceso marcado por la transformación del modo de producir la vivienda, y marcando la dirección en las formas de consumirla, por otra. Así, pues, los poderes públicos (el Estado, La Comunidad de Madrid, el Ayuntamiento de Madrid,...) no se han limitado a tener una posición neutral como gestor del "bien común", sino que se han convertido en directores o, en su caso, mediadores de intereses diversos (han marcado tanto "ex ante" como "ex post" las líneas directrices que marcan el sector inmobiliario). El núcleo urbano de Madrid se ha ido conformando dentro de una extensa área metropolitana conformada por unos trescientos treinta y tres municipios (algunos de ellos concretados en este estudio de manera pormenorizada, como ha sido el caso de Aranjuez, o Chinchón). Esta realidad, 
no solo ha favorecido, sino que también ha promovido que tanto en la ciudad de Madrid como núcleo principal del área metropolitana enunciada, como en el resto de municipios, se hayan creado todo un conjunto de relaciones de carácter económico, político, social y también cultural (amén de muchos otros diferentes), que hacen que las actuaciones de los poderes públicos deban de ser analizadas, no de manera individual y compacta, sino en la consideración de sus repercusiones sobre el conjunto de las distintas áreas territoriales que delimitan a la ciudad asentada.

Así, pues, la triada crecimiento urbano-políticas de vivienda-transformación del sector inmobiliario, desempeñan un papel protagonista en el proceso descrito, en relación directa con la idea según la cual la rentabilidad relativa de este sector se apoya en componentes no siempre ligados a la producción del producto (es decir, partiendo de las condiciones financieras, se basan, sobre todo en las posibilidades de las rentas que dimanen del "suelo"). En consideración a esta actuación de los poderes públicos (en unión también de la actuación y proyección de la iniciativa privada), nos encontramos en estos momentos, con el denominado "Madrid, Nuevo Norte". Este proyecto se enmarca dentro de los ejemplos de esas relaciones económicas, sociales, políticas y culturales arriba referenciadas, que suponen que en los momentos actuales (cuestión que se fragua ya desde hace unos años), se esté llevando a cabo una de las mayores operaciones urbanísticas de todo el mundo (sírvanse de ejemplo iniciativas urbanísticas como son las del barrio de Hudson Yards en la ciudad de Nueva York, el complejo de negocios desarrollado en la City londinense denominada como la Canary Wharf, la significativa plaza pública e intersección del tráfico rodado del centro de la ciudad de Berlín reconocida como la Postdamer Platz de Berlín, o el barrio de negocios ubicado en la zona oeste de la ciudad francesa de París conocido como La Defense). Operación urbanística la del "Madrid, Nuevo Norte", que surge de la intención de visibilizar el esfuerzo de la ciudad de Madrid por construir, erigir y posteriormente desarrollar un espacio urbano que se adecue y amolde a las exigencias de la ciudadanía, de habitar en una urbe competitiva, moderna y contemporánea (pese a que ello, como no puede ser de otra forma, traiga consigo una gran cantidad de impactos sobre la ciudad de Madrid, y genere procesos inherentes a la propiedad especulativa). Esta se va a desarrollar en el marco de lo que ha dado en denominarse, tradicionalmente, "Operación Chamartín”, en unos espacios geográficos en transformación, con importantísimos cambios de funciones, tras la recalificación del suelo (este enfoque del crecimiento a partir de la oferta que se genere tras la actuación urbanística, pondrá en crisis la búsqueda de los factores de localización de la demanda, desempeñando un papel preponderante las variables exógenas que condicionan la oferta de vivienda, de tal forma que el proyecto en cuestión da todo esto por resuelto, ya que marca cuántas se van a construir, dónde, cómo y cuáles serán los espacios resultantes - incluyendo los integrantes del futuro Tercer Espacio. La cada vez más posible materialización del denominado "Madrid, Nuevo Norte", con su definitiva aprobación por parte Consejo de Gobierno de la Comunidad de Madrid el pasado 25 de mayo del 2020, supondrá la tangible puesta en marcha de un "proyecto de regeneración urbana" que, sin lugar a dudas (y visto desde sus aportes beneficiosos como desde sus impactos no tan provechosos), transformaría la ciudad que ostenta la capitalidad de España, reformando por completo el espacio 
urbano de esa zona de la urbe madrileña. En concreto la envergadura de este Madrid Nuevo Norte quedaría vislumbrada por la magnitud de una edificación que ocuparía unos 2,66 millones de $\mathrm{m}$ de superficie, repartida en sus usos unos 1,05 millones de $\mathrm{m}^{2}$ para su uso residencial y otros 1,61 millones de $\mathrm{m}^{2}$ para su uso carácter no residencial, siendo este último caso (y pese a no estar del todo concretado) propuesto para oficinas que se integrarían dentro del denominado como "Centro de Negocios de Chamartín", y lo que hipotéticamente supondría un aumento significativamente relevante de la oferta, casualmente en los lugares con más demanda de ese tipo de espacios y en donde más insuficiencia y necesidad hay de los mismos ${ }^{2}$.

Superada entonces la aprobación primero por unanimidad de los partidos de la ciudad de Madrid (en Pleno del Ayuntamiento), en el mes de julio del 2019, y tras la aprobación definitiva llevada a cabo por el gobierno de la Comunidad Autónoma de Madrid, se daría cumplimiento al último paso administrativo exigible para que el proyecto urbanístico sea indiscutiblemente validado, y puedan concluirse las actuaciones correspondientes con las fases denominadas de planeamiento y así poder comenzar la nueva fase calificada de ejecución. Fase esta de ejecución cuyo propósito primordial, y previo a cualquier realización de las obras, se traduce en la composición escrita de los proyectos de urbanización y reparcelación correspondientes con las nuevas propuestas a desarrollar ${ }^{3}$.

\section{3. “MADRID, NUEVO NORTE”: PASADO, PRESENTE Y FUTURO DESDE UNA PERSPECTIVA LEGAL}

El proceso de generación y ocupación de suelo urbano, en Madrid, consecuencia directa de las relaciones directas entre "el sistema" (social, económico y político) y su configuración en el espacio, en una ciudad que en los últimos sesenta años ha pasado de ser una ciudad densa y concentrada aislada en su propio entorno geográfico, a tener funciones de índole diverso, a nivel mundial, por lo que no es de extrañar que haya multiplicado por muchos dígitos, a lo largo de esos años, el suelo que ocupa en la actualidad, y que necesite más, ya que se ha transformado en una aglomeración urbana de complejidad estructural creciente. La reordenación de la zona norte de la ciudad de Madrid empieza a comprenderse como una realidad cada vez más palpable. Sin embargo, el arduo camino, administrativo, jurídico y también político que ha tenido que recorrerse para hacer posible que finalmente se diera por parte de los poderes públicos luz verde a la materialización de un proyecto de la envergadura del que aquí se está analizando, se retrotrae a casi tres décadas atrás (ver figura $\mathrm{n}^{\mathrm{O}} 1$ ).

2 Subdirección General de Análisis Socioeconómico Dirección General de Economía y Sector Público. Ayuntamiento de Madrid. Área de Gobierno de Economía y Hacienda. (2018). Madrid Nuevo Norte. Análisis de Impacto. En:https://www.madrid.es/UnidadesDescentralizadas/UrbanismoyVivienda/Urbanismo/Destacamos/ ficheros/Analisis_impacto_MNN.pdf.

3 Distrito Castellana Norte (2020). La Comunidad de Madrid anuncia la aprobación definitiva de Madrid Nuevo Norte para el próximo 25 de marzo. Publicado el 9 de marzo, en: https://distritocastellananorte.com/lacomunidad-de-madrid-anuncia-la-aprobacion-definitiva-de-madrid-nuevo-norte-para-el-proximo-25-de-marzo/. 


\section{Figura $\mathbf{n}^{0} 1$ \\ MAPA LOCALIZACIÓN ÁREA DE ESTUDIO: MADRID NUEVO NORTE}

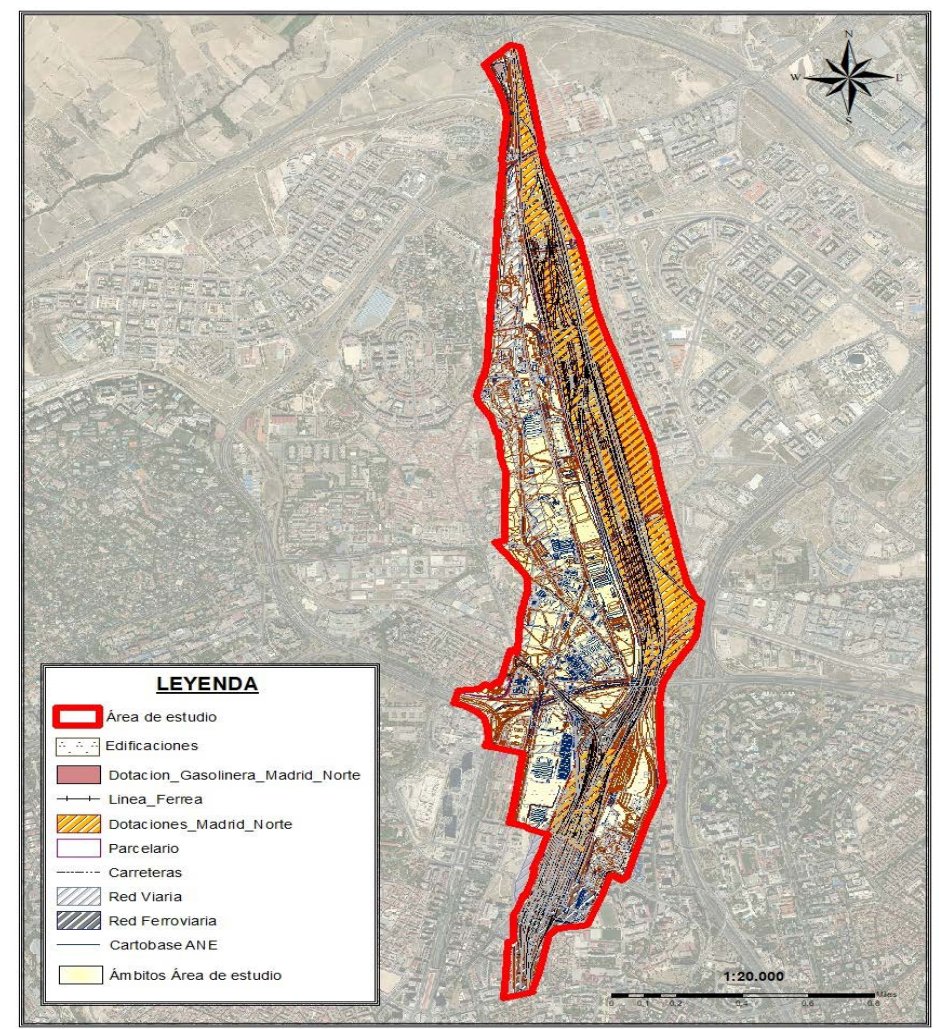

Fuente: Elaboración propia.

La historia urbanística que ha dado paso al denominado como "Madrid, Nuevo Norte" comienza a finales del siglo pasado cuando alrededor de los años noventa, se estudia programar para la estación madrileña de Chamartín y sus alrededores, una remodelación exhaustiva que transforme por completo la fisonomía de la misma. Finalmente, este planteamiento, no consiguió, por cuestiones diversas, que tuviera el suficiente reconocimiento institucional para que se llevara a cabo un plan urbanístico que resolviera la situación en la que se encontraba unos terrenos que ocupaban unos tres millones de metros cuadrados, y en unos suelos que comprendían la conocida como "Área de Planeamiento Específico, APE 08.03 Prolongación de la Castellana”; y cuya operación para ser más exactos sería comúnmente conocida como "Operación Chamartín"; la cual posteriormente seria renombrada con la denominación que en la actualidad permanece de "Madrid, Nuevo Norte", lo que supondría no tanto un cambio de denominación sino más bien un replanteamiento en la dirección para las distintas propuestas de ordenación de esta zona norte de la ciudad de Madrid, que habían sido anteriormente sugeridas (ver figuras $\mathrm{n}^{\circ} 2 \mathrm{y} \mathrm{n}^{\circ} 3$ ). 
Figura $\mathbf{n}^{0} 2$

REMODELACIÓN MADRID NUEVO NORTE: ELEMENTOS DEL PAISAJE Y SU EVOLUCIÓN DESDE 1956-1957 HASTA LA ACTUALIDAD

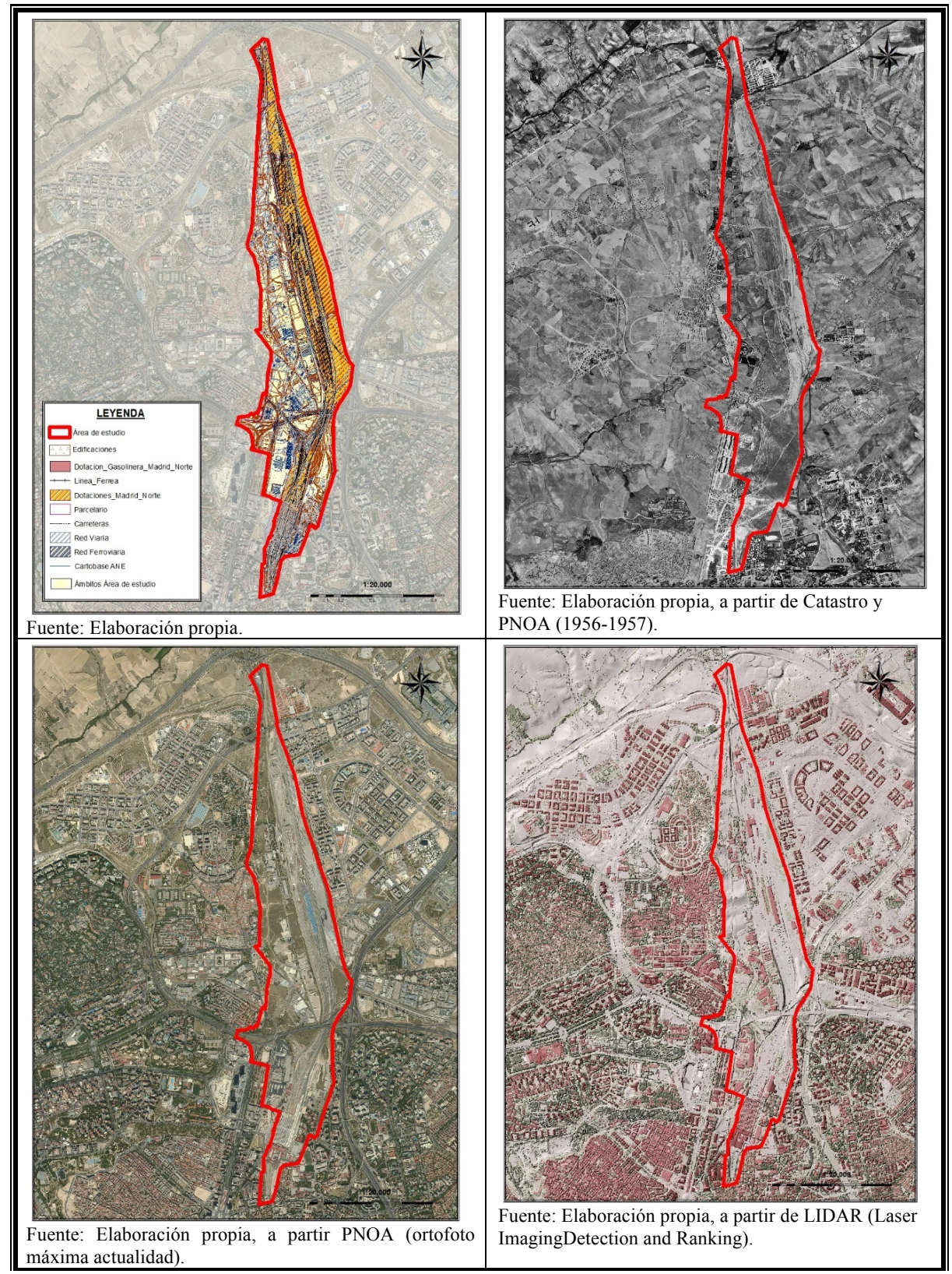


La propiedad exacta de los terrenos en los que iba inicialmente a plantearse lo que posteriormente iba a ser el Proyecto de generación urbana de "Madrid, Nuevo Norte", pertenecían en su mayor parte a la actualmente conocida como empresa pública ADIF, la cual obtendría la titularizad de los mismos mediante la expropiación realizada para destinar dichos terrenos a los Sistemas Generales Ferroviarios en el año 1941, manteniéndose dicha circunstancia hasta los momentos actuales en los que nos encontramos (de hecho la estación de Chamartín que hoy en día es apreciada, sería levantada en lo que por los años sesenta comprendería un espacio urbano sin ningún tipo de ocupación concreta).

\section{Figura n' 3 \\ ÁMBITOS DE ACTUACIÓN: CONVENIOS APE Y APR DE LAS FASES DEL PROYECTO MADRID NUEVO Y PLANO DE LOS NUEVOS USOS DEL SUELO}

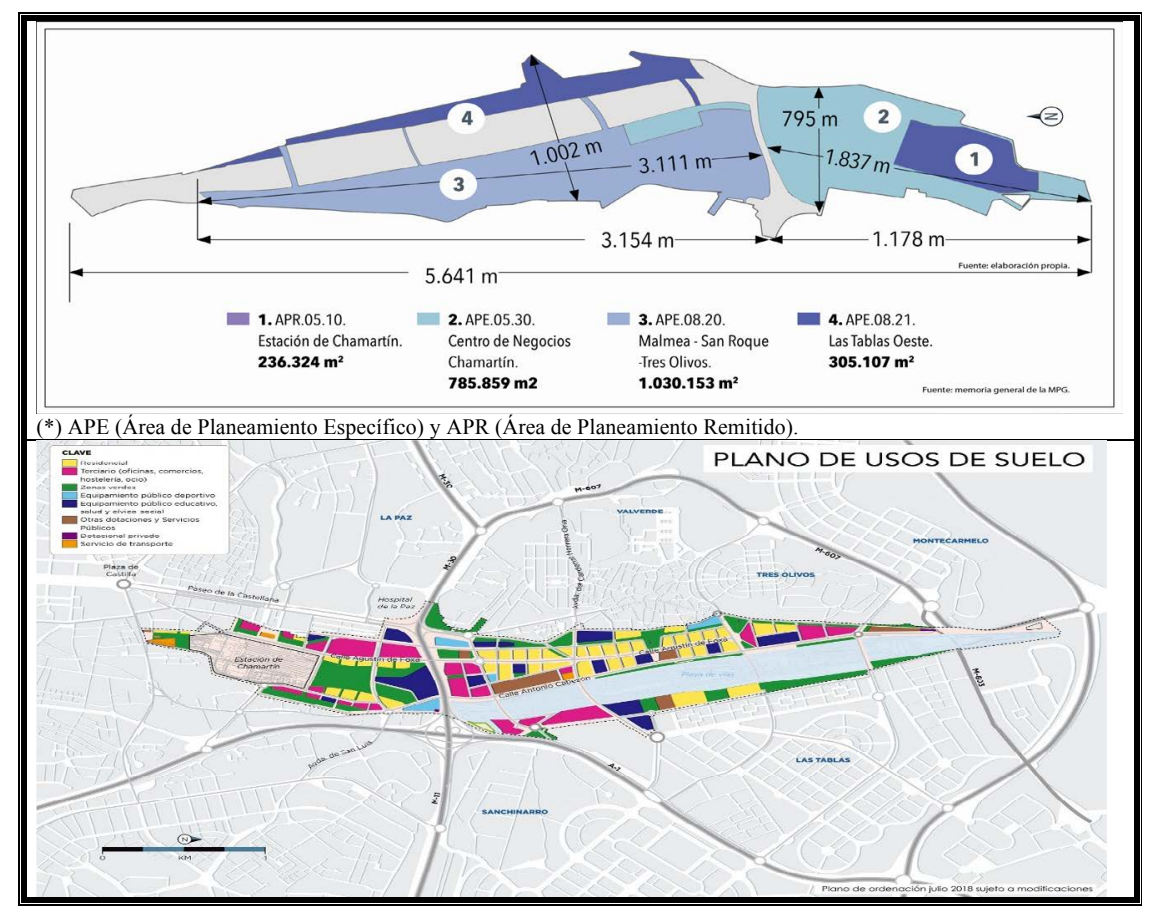

Fuente: Distrito Castellana Norte (2020).

Por lo tanto, el pasado de este proyecto parte de un concurso realizado en los años noventa por la entidad pública denominada como RENFE (actualmente como se ha señalado en las líneas anteriores denominada como empresa pública ADIF), que junto con el apoyo del organismo gubernamental del que dependía (esto es del anteriormente identificado como Ministerio de Fomento), sacarían a delante un modelo decisorio en el que poder sustentar la elección de los correspondientes derechos de edificación sobre el 
suelo del que era propietaria. De este procedimiento surgiría un convenio con la actualmente denominada Distrito Castellana Norte (por aquella época conocida como "sociedad mercantil DUCH- Desarrollos Urbanísticos de Chamartín”), que comprendía tanto a la empresa Inmobiliaria San José como a la entidad bancaria de BBVA (anteriormente banco Argentaria), para que llevara a buen término la realización de privatizar los aprovechamientos de los terrenos o mejor dicho de los suelos de titularidad pública.

\section{METODOLOGÍA DE INVESTIGACIÓN}

Tal y como podemos comprobar en las variables integrantes de la susodicha Metodología, los espacios residuales que forman parte de los Lostspaces (los antiespacios sin forma y sin uso), predominan en este espacio geográfico. Es la tierra de nadie a lo largo de los bordes de las autovías, de cuya conservación nadie se ocupa, y que nadie usa. Son también los frentes litorales abandonados, las playas de vías de ferrocarril, los recintos militares abandonados, los complejos industriales que se han trasladado a los suburbios para tener mejores accesos e impuestos más bajos. Son los terrenos vacantes en los centros urbanos, resultantes de las demoliciones que, por diversas razones, nunca fueron reconstruidos. Son las áreas residuales entre distritos y los strips comerciales espontáneos que emergen sin que nadie se haya dado cuenta. Los espacios perdidos son también los parques deteriorados y los proyectos de vivienda pública marginales que tienen que ser reconstruidos porque no sirven a sus propósitos. Desde esta perspectiva el desarrollo y aplicación, y la metodología desarrollada coadyuvará al estudio y conocimiento de las posibles consecuencias emanadas de la intervención en el territorio, y, el tratamiento del denominado "tercer paisaje" (cobrando especial relevancia el valor paisajístico del territorio en el ámbito de la sostenibilidad).

\section{Figura n' 4 \\ METODOLOGÍA PROPUESTA. ANÁLISIS TERRITORIAL (MADRID NORTE)}

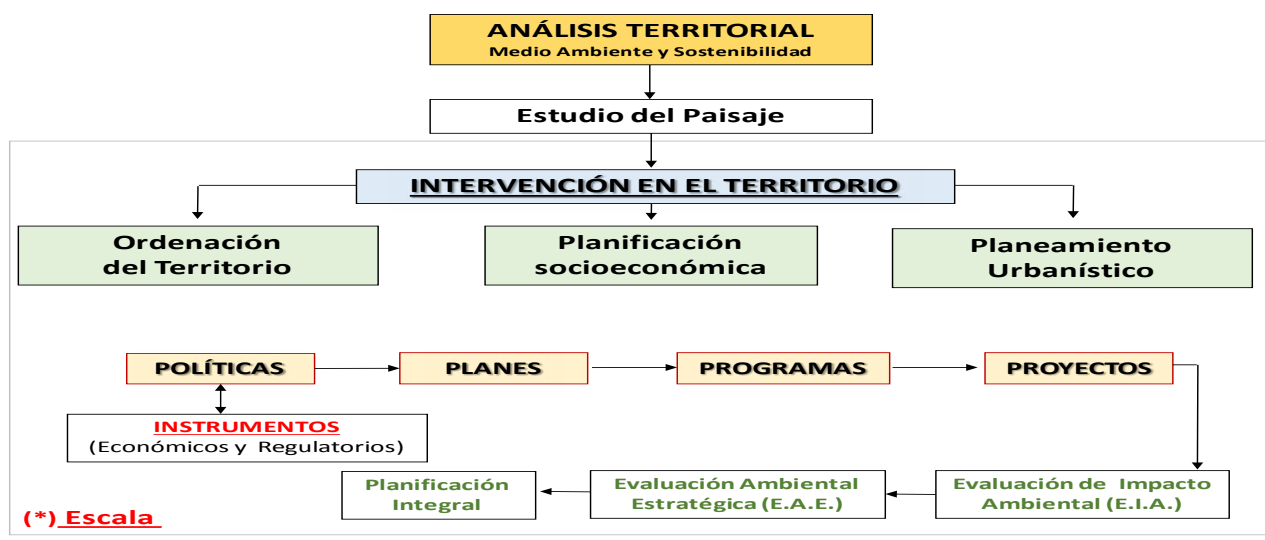

Fuente: Elaboración propia. 


\section{Figura $\mathbf{n}^{0} 5$ \\ METODOLOGÍA PROPUESTA. ANÁLISIS DEL TERCER PAISAJE (MADRID NORTE)}

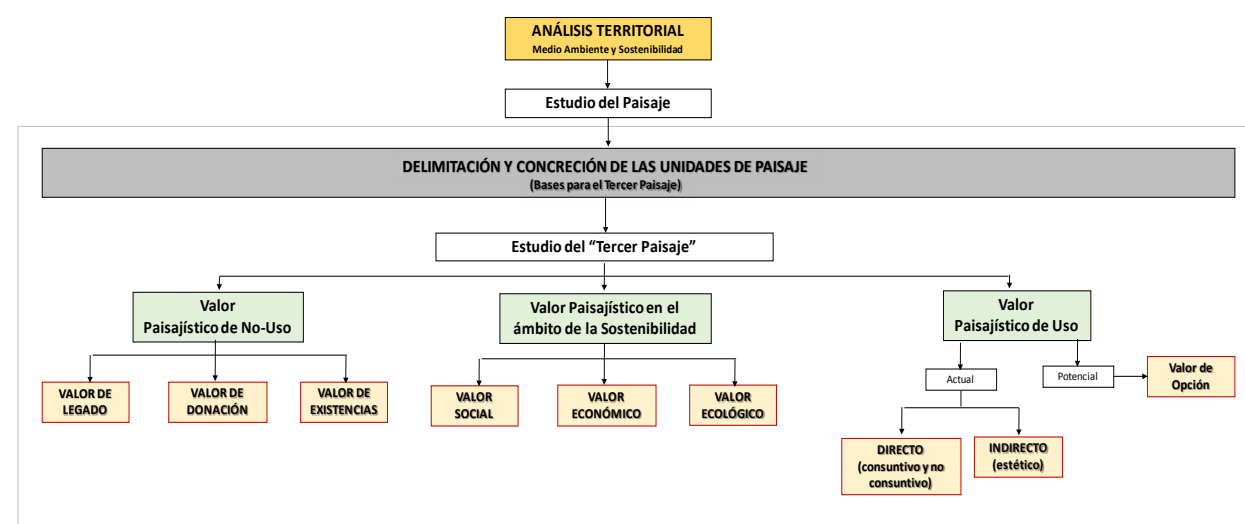

Fuente: Elaboración propia.

\section{LOS CONTEXTOS DEL "PLAN CHAMARTÍN"}

En consonancia con los hechos descritos dentro de este orden cronológico, se puede afirmar que lo que inicialmente iba a ser un plan de generación de usos terciarios entorno a la estación de Chamartín, y que iba a ser parcialmente financiado a través de los beneficios obtenidos de la venta de los aprovechamientos (los cuales se pretenderían ser empleados para la correspondiente remodelación de la estación de Chamartín, que junto con la estación madrileña de Atocha, conformaría el principal nodo ferroviario de la capital de España); todo ello iba a ser orientado por una empresa de carácter privado como es Distrito Castellana Norte, y por una filial de la entidad bancaria del BBVA la cual disponía por concesión de los derechos de los terrenos propiedad de la empresa pública denominada como ADIF (los cuales se adjudicarían a través del concurso público del año de 1993) ${ }^{4}$.

El propósito de viabilidad para poder llevar a cabo las remodelaciones pertinentes en la susodicha estación de Chamartín, la aspiración para poder efectuar el remate del Norte de la urbe madrileña, y el deseo en llevar a cabo la ampliación hacia el norte del eje de la Castellana, iban a ser en un principio el origen del surgimiento del mencionado concurso, infiriéndose así como la intención de producir y obtener recursos económicos para su posterior inversión en la operación concerniente con la estación, iba a convertirse finalmente en el objetivo subsidiario del anteriormente mencionado convenio. Sin embargo este objetivo de reinvertir en la estación los beneficios previamente conseguidos, inmediatamente pasaría a formar parte de los objetivos subsidiarios, pues la dimensión de esta actuación urbanística

4 Calvo, J.M. (2019). Un Nuevo Norte para un nuevo Madrid. Área de Gobierno de Desarrollo Urbano Sostenible - Ayuntamiento de Madrid. En:

https://www.coam.org/media/Default\%20Files/fundacion/biblioteca/revista arquitectura-100/2018-2019/ docs/revista-articulos/revista-arquitectura-2018-n376-pag54-57.pdf. 
sugería la generación de recursos económicos de los que querían beneficiarse la aludida sociedad inversora, de ahí que el entusiasmo por la edificación se haya visto acrecentada con el paso del tiempo desde que tuviera lugar la firma del convenio en el año 1993 hasta los momentos actuales. Desde que tuvo lugar en este año la firma del renombrado convenio han ido sobreviniendo diversas diligencias de índole urbanístico como son:

\section{A). La puntual Modificación del Plan General de Ordenación Urbana de Madrid} del año 1997. En este sentido y teniendo como antecedente el Plan General de Ordenación Urbana de Madrid de 1985, su modificación del año 1995 y la repercusión de la sentencia 1850/2001 de 27 de noviembre; tendría lugar la aprobación del Plan General de Ordenación Urbana de Madrid del año 1997, en cual se integraría dentro del correspondiente ámbito de actuación a los terrenos anejos a la estación de Chamartín, la prolongación del eje de la Castellana hacia el norte y también los terrenos concernientes con Fuencarral, ocasionando con ello un incremento de los suelos y la superficie sometidas a actuación que supondría un paso de las sesenta y dos hectáreas a unas trescientas doce Hectáreas. Coincidiendo además este mismo año con la conformación del consorcio Urbanístico, integrado por un conjunto de agentes, siendo los mismos el por entonces Ministerio de Fomento (nivel de gobierno de ámbito nacional), la Comunidad de Madrid (nivel de gobierno de ámbito regional o autonómico), y el Ayuntamiento de Madrid (perteneciente al nivel de gobierno local o municipal), junto con la entidad pública RENFE (empresa pública $\mathrm{ADIF}$ ), y la sociedad mercantil $\mathrm{DUCH}$, cuyo propósito fundamentar se sustentaba en llevar a cabo la negociación de los aspectos del proyecto que a continuación pasaría a denominarse "Operación Prolongación de la Castellana".

Para una mejor compresión de la magnitud de esta operación se ha de mencionar por un lado el espacio físico que abarcaba y abarca dicha iniciativa, que concierne a los barrios correspondientes a Castilla, el lado oeste de Las Tablas, Chamartín y Valverde, junto con el distrito de Fuencarral-El Pardo, y territorios anejos a la estación de Chamartín. Y por el otro lado la consideración de las entidades involucradas (conformadas por un total de empresas públicas, propietarios en el anonimato, y Administraciones), que desde el principio, serían reconocidas de la manera siguiente ${ }^{5}$ :

1). Empresa pública ADIF con más del noventa y cuatro por ciento de la titularidad de la propiedad del suelo.

2). Propietarios de diversa índole anónimamente considerados, que contarían con más del veinticinco por ciento de la propiedad de los terrenos.

3). El Ayuntamiento de Madrid, organismo dedicado a realizar las aprobaciones pertinentes de los Planes Parciales y las respectivas modificaciones del Plan General de Ordenación Urbana de Madrid, y que disponía de la titularidad de ardedor de un diez por ciento de la propiedad del suelo.

4). La Empresa Municipal de Trasporte de Madrid (EMT), con alrededor del seis por ciento de la titularidad de los suelos.

5 Datos obtenidos a partir de la Información mostrada en la parte correspondiente con la memoria del Proyecto denominado Madrid Nuevo Norte. 
5). La empresa pública española conocida como Canal de Isabel II, la cual se encarga de la gestión del ciclo integral de los recursos hídricos, y que poseía alrededor de un seis por ciento de la propiedad de los terrenos.

6). La Empresa de capital público legalmente conocida como Sociedad Estatal Correos y Telégrafos, S.A., S.M.E, que dispondría de alrededor de un dos por ciento de la titularidad de la propiedad de los suelos.

7). La Comunidad Autónoma de Madrid, que con algo más del uno por ciento de la propiedad de los suelos, se encargaría de realizar las aprobaciones imprescindibles concernientes con la modificación de la Ley del Suelo.

8). El anteriormente conocido como Ministerio de Fomento, que poseía casi un uno por ciento de la propiedad de los terrenos.

9). Plataformas vecinales, que por medio del asociacionismo defenderían los intereses vecinales propios frente a los de las empresas inmobiliarias involucradas.

10). El sector financiero representado por la entidad privada denominada Distrito Castellana Norte, en donde los máximos promotores para la realización del proyecto lo conformarían la entidad bancaria BBVA que intervendría con alrededor del setenta y tres por ciento de la participación, junto con la empresa inmobiliaria San José con casi el veintiocho por ciento de dicha participación.

En este contexto la Modificación Puntual del Plan General de Ordenación Urbana de Madrid concerniría al entorno de la "Colonia de Campamento" y a la "Prolongación de la Castellana" y que en el año 2018 se conocería que respecto al primero de ellos (el referente a la Colonia de Campamento), se encontraría en situación conveniente para cursar de manera inmediata a la denominada fase de ejecución, al disponer del conjunto de precisiones urbanísticas jurídicamente exigibles. En ese mismo año, la redacción del ya por entonces actual Plan General de Ordenación Urbana de Madrid Modificado puntualmente, dispondría en cuanto al segundo de los ámbitos (es decir, respecto a la Prolongación de la Castellana), que tendría que desarrollarse a través de la correspondiente tramitación previa de un Plan Parcial de Reforma Interior (denominado como PPRI).

B). La celebración de dos convenios Urbanísticos por parte de las entidades involucradas finalmente firmados en los años 2008 y 2011; la aprobación en el año 2011 de un Plan Parcial definitivamente anulado por los tribunales de justicia y la realización en el año 2015 de un segundo Plan Parcial que al final no obtuvo la aprobación del Pleno del Ayuntamiento de Madrid (siendo esta resolución recurrida por la entidad privada denominada Distrito Castellana Norte).

En el año 2008 se llevaría a cabo un Convenio en el que participarían mediante firma la Comunidad Autónoma de Madrid, el por entonces conocido como Ministerio de Fomento, el Ayuntamiento de, Madrid, la sociedad mercantil Desarrollo Urbanístico Chamartín (conocida como DUCH) y el Administrador de las Infraestructuras Ferroviarias (actualmente conocido como ADIF), Renfe-Operadora. Siendo en el año 2011 cuando tendría lugar la aprobación del Plan Parcial de Reforma Interior dedicado desarrollar la conveniente operación de transformación y reciclaje urbano, y que posteriormente tras un pronunciamiento del Tribunal Superior de Justicia de Madrid del año 2013, seria parcialmente anulado. Cuestión algo parecida, cuando el Plan Parcial de Reforma Interior, tras la aprobación ini- 
cial de la Junta de Gobierno el día 19 de febrero de 2015 para que fuera revisado, no sería finalmente aprobado por no contar con el consentimiento el 25 de mayo del 2016 del Pleno del Ayuntamiento de Madrid. Posteriormente y tras todo este cúmulo de vicisitudes, el por entonces Ministerio de Fomento, el consistorio de la ciudad de Madrid y la sociedad Distrito Castellana Norte (conformada por la inmobiliaria San José, y la entidad bancaria BBVA), resolverían acordar el 27 de julio del 2017, la creación de un proyecto de nuevo cuño que pasaría a ser denominado como "Madrid Nuevo Norte". Dicho proyecto que diferenciaría cuatro tipos de sectores para la actuación, estos son (los denominados APE y el APR):

1). El relacionado con el Centro de Negocios Chamartín (APE)

2). El desarrollado al Oeste del barrio de las Tablas (APE).

3). El correspondiente con la Estación de Chamartín (APR).

4). Y, además, el relativo con Malmea - San Roque - Tres Olivos (APE).

Se incardinaría en relación con la ordenación determinada por esta modificación del Plan General, no solo a tratar lo relacionado con los denominados APE, es decir a la construcción de las distintas zonas verdes, edificaciones o equipamientos, o a abordar el concerniente APR, con la realización del planeamiento de los servicios ferroviarios de la estación (con el respectivo Plan Parcial y sus respectivos proyectos), sino que además con el nuevo proyecto se propondría incorporar una estrategia global de intervención con la Modificación del Plan General de Ordenación Urbana de Madrid6 ${ }^{6}$.

Descritos algunos aspectos concernientes con las relaciones existentes entre el proyecto analizado, los acontecimientos históricos relacionados con el mismo y algunos aspectos vinculados con los ámbitos territoriales concernientes con la Autonomía, el municipio, el distrito, los barrios y la zona concreta de actuación en los que tendría que ser desarrollado y ejecutado dicha operación urbanística; se hace imprescindible no solo encuadrar sino organizar a través de la legislación existente, las diferentes actividades e intervenciones que durante estas décadas se han orientado a que se aprobara el denominado actualmente

6 En relación a todos estos acontecimientos resulta interesante acudir al Informe titulado Evaluación de los efectos de la propuesta Madrid Nuevo Norte (APR 08.03 Prolongación de la Castellana) en las infraestructuras de transporte del área metropolitana de Madrid; elaborado por el Instituto DM y Ecologistas en Acción Madrid y disponible en: https://spip.ecologistasenaccion.org/IMG/pdf/informe-movilidad-madrid-nuevo-norte.pdf. En dicho informe se incorpora tras mostrar la situación del Plan Parcial en los años 2011 y 2015, la información concerniente con las propuestas, esclareciendo respecto a ellas como « Después de esta última paralización en 2015, se han elaborado dos propuestas diferentes en cuanto a volumen edificable, infraestructuras afectadas y ordenación: Una primera, la denominada Madrid Puerta Norte, condensada en un documento explicativo sin valor legal, presentada por el Ayuntamiento a mediados de 2016, que fue rechazada tanto por ADIF-Ministerio de Fomento como por DCN. Una segunda propuesta, la denominada MNN, presentada en julio de 2017 a modo de acuerdo entre el Ayuntamiento, el Ministerio de Fomento y la inversora DCN. Esta última se condensa en el texto del acuerdo de 5 páginas que establece en grandes líneas las magnitudes en términos de edificabilidad, cesiones obligatorias e inversiones en infraestructuras, así como los compromisos de cada parte. Las principales cuestiones contenidas en el Acuerdo hecho público el 27 de Julio de 2017, en materia de movilidad, son: la ampliación de la Estación de Chamartín, la cubrición de las vías del tren, la modificación de los nudos de Fuencarral y de Manoteras, la conexión entre los barrios limítrofes separados por las vías, el traslado de las cocheras de la Empresa Municipal de Transportes, la ampliación de la línea L7 hacia el norte, y la ubicación de 1,73 millones de $\mathrm{m} 2$ de oficinas y $1,1 \mathrm{~m} 2$ de viviendas. Todas son relevantes para la movilidad del conjunto de la ciudad y conforman el objeto del análisis del presente estudio de movilidad» (Capítulo 1: La Operación Chamartín: antecedentes y contexto. Epígrafe 1.1. Origen y breve historial de la operación. Páginas 3 a la 4). 
como "Madrid, Nuevo Norte". En este sentido remitiéndonos a los cuerpos normativos actualmente vigentes en materia de urbanismo y que inciden sobre el tema urbanístico aquí estudiado se corresponden con:

\subsection{Legislación urbanística actualmente vigente}

A). Normativa Urbanística de ámbito estatal:

A.1. Real Decreto Legislativo 7/2015 de 30 de octubre, por el que se aprueba el texto refundido de la Ley de Suelo y Rehabilitación Urbana.

A.2..Real Decreto 106/2018, de 9 de marzo, por el que se regula el Plan Estatal de Vivienda 2018- 2021.

A.3. Real Decreto 1492/2011 de 24 de octubre, por el que se aprueba el Reglamento de Valoraciones de la Ley de Suelo.

A.4. Real Decreto 2159/1978 de 23 de junio, por el que se aprueba el Reglamento de Planeamiento Urbanístico.

B). Normativa Urbanística de ámbito Estatal Supletoria (Ministerio de Fomento):

B.1. Real Decreto 3288/1978 de 25 de agosto, por el que se aprueba el Reglamento de Gestión Urbanística para el desarrollo y aplicación de la Ley sobre Régimen del Suelo y Ordenación Urbana.

B.2. Real Decreto 2187/1978 de 23 de junio, por el que se aprueba el Reglamento de Disciplina Urbanística para el desarrollo y aplicación de la Ley sobre Régimen del Suelo y Ordenación Urbana.

B.3. Real Decreto 1346/1976 de 9 de abril, por el que se aprueba el Texto Refundido de la Ley sobre Régimen del Suelo y Ordenación Urbana.

Estas normas de ámbito estatal y de naturaleza supletoria, serán aplicadas en los supuestos que no se encuentran desarrollados por las Leyes Urbanísticas, y pos aquellos Reglamentos correspondientes a cada Comunidad Autónoma, que en este caso se refiere a los Reglamentos de la Comunidad Autónoma de Madrid (y siempre que no sean opuestos a los mismos). Me refiero a los citados Real Decreto 1346/76, de 9 de abril, por el que se aprueba el Texto Refundido de la Ley sobre Régimen del Suelo y Ordenación Urbana y sus Reglamentos de desarrollo en los artículos que no han sido derogados por el RD 304/93, de 26 de febrero, por el que se aprueba la tabla de vigencias de los Reglamentos de Planeamiento, Gestión Urbanística, Disciplina Urbanística, Edificación Forzosa y Registro Municipal de Solares y Reparcelaciones, en ejecución de la disposición final única del texto refundido de la Ley sobre Régimen del Suelo y Ordenación Urbana.

C). Normativa Urbanística de ámbito Autonómico:

C.1. Decreto 1/2016, de 5 de enero, del Consejo de Gobierno, por el que se aprueba el Reglamento de Organización y Funcionamiento Interno de la Comisión de Urbanismo de Madrid.

C.2. Ley 8/2009, de 21 de diciembre, de Medidas Liberalizadoras y de Apoyo a la Empresa Madrileña. 
C.3. Decreto 92/2008, de 10 de julio, por el que se regulan las modificaciones puntuales no sustanciales de planeamiento urbanístico.

C.4. Ley 9/2001 17 julio, del Suelo de la Comunidad de Madrid.

C.5. Ley 7/2000, de 19 de junio, de Rehabilitación de Espacios Urbanos Degradados y de Inmuebles que deban ser objeto de Preservación.

C.6. Decreto 131/1997, de 16 de octubre, por el que se fijan los requisitos que han de cumplir las actuaciones urbanísticas en relación con las infraestructuras eléctricas.

C.7. Decreto 71/1997, de 12 de junio de 1997, por el que se aprueba el Reglamento de Organización y Funcionamiento del Jurado Territorial de Expropiación Forzosa de la Comunidad de Madrid.

C.8. Ley 9/1995 28 marzo, de Medidas de Política Territorial, Suelo y Urbanismo.

C.9. Ley 8/1985 4 diciembre, que deja sin aplicación en el ámbito de las Comunidad, la figura de los proyectos de delimitación de suelo urbano, regulada en el Real DecretoLey 16 octubre 1981, de adaptación de los planes generales de ordenación.

D). Normativa Urbanística de ámbito Municipal:

D.1. Plan General De Ordenación Urbana, de 17 de Abril de 1997.

D.1.1. Modificación Puntual del Plan General de Ordenación Urbana de Madrid de 1997 en los ámbitos de planeamiento: APR 08.03 "Prolongación de la Castellana" y APE 05.07 "Colonia Campamento" para la definición de los determinaciones y parámetros de ordenación de la operación urbanística "Madrid Nuevo Norte".

Este conjunto normativo, nos introduciría a su vez a una de las cuestiones más trascendentales para la materia concerniente con el urbanismo, y que hace mención al tema de la sostenibilidad. Remitiéndonos a la Ley 8/2007, de 28 de mayo, de suelo, posteriormente ratificada por el Real Decreto Legislativo 2/2008, de 20 de junio, por el que se aprueba el texto refundido de la ley de suelo, ya se podía vislumbrar la atención a esta cuestión, y en concreto cuando en el apartado segundo de su parte introductoria se mostraría como «la del urbanismo español contemporáneo es una historia desarrollista, volcada sobre todo en la creación de nueva ciudad. Sin duda, el crecimiento urbano sigue siendo necesario, pero hoy parece asimismo claro que el urbanismo debe responder a los requerimientos de un desarrollo sostenible, minimizando el impacto de aquel crecimiento y apostando por la regeneración de la ciudad existente» ${ }^{7}$, y principalmente cuando en su artículo 15 , titulado como "Evaluación y seguimiento de la sostenibilidad del desarrollo urbano", se especifica que «Los instrumentos de ordenación territorial y urbanística están sometidos a evaluación ambiental de conformidad con lo previsto en la legislación de evaluación de

7 Real Decreto Legislativo 2/2008, de 20 de junio, por el que se aprueba el texto refundido de la ley de suelo. Cuestión que también queda demostrada en el artículo 15 relativo a la Evaluación y seguimiento de la sostenibilidad del desarrollo urbano o en su Disposición transitoria cuarta. Referenciada como Criterios mínimos de sostenibilidad en la que se señalaría como « Si, trascurrido un año desde la entrada en vigor de la Ley 8/2007, de 28 de mayo, de Suelo, la legislación sobre ordenación territorial y urbanística no estableciera en qué casos el impacto de una actuación de urbanización obliga a ejercer de forma plena la potestad de ordenación, esta nueva ordenación o revisión será necesaria cuando la actuación conlleve, por sí misma o en unión de las aprobadas en los dos últimos años, un incremento superior al 20 por ciento de la población o de la superficie de suelo urbanizado del municipio o ámbito territorial». 
los efectos de determinados planes y programas en el medio ambiente y en este artículo, sin perjuicio de la evaluación de impacto ambiental de los proyectos que se requieran para su ejecución, en su caso» (art.15.1); incorporando por tanto a través de esta vía la necesidad de que los instrumentos de ordenación territorial y urbanística sean sometidos preceptivamente tanto a la evaluación ambiental como a la evaluación económica. Más adelante con la aprobación del actualmente vigente Real Decreto Legislativo 7/2015, de 30 de octubre, por el que se aprueba el texto refundido de la Ley de Suelo y rehabilitación Urbana (que derogaría a la normativa anteriormente citada), se consolidaría dicha pretensión al dictaminar como Principio de desarrollo territorial y urbano sostenible que «Los poderes públicos formularán y desarrollarán, en el medio urbano, las políticas de su respectiva competencia, de acuerdo con los principios de competitividad y sostenibilidad económica, social y medioambiental, cohesión territorial, eficiencia energética y complejidad funcional, procurando que, esté suficientemente dotado, y que el suelo se ocupe de manera eficiente» $\left(\right.$ art.3.3) ${ }^{8}$, refiriéndose en consecuencia tanto a exigencia hacia los poderes públicos para desarrollar y formular las políticas de sus respectivas competencias a tenor de los principios de competitividad y sostenibilidad; como también aludiendo a que el desarrollo sostenible debe de ser capaz de proporcionar una serie de beneficios relacionados con los usos racionales de los recursos, la seguridad de las personas, la cohesión social, o la protección del medio ambiente, entre otras.

En correspondencia con estos propósitos incardinados hacia la denominada sostenibilidad, el marco normativo tendente a ser aplicado nos encuadra dentro de esta finalidad, y esencialmente cuando por parte del vigente Real Decreto Legislativo 7/2015, de 30 de octubre, por el que se aprueba el texto refundido de la Ley de Suelo y rehabilitación Urbana, se determina de manera particularizada la "Evaluación y seguimiento de la sostenibilidad del desarrollo urbano, y garantía de la viabilidad técnica y económica de las actuaciones sobre el medio urbano", diferenciando como «La documentación de los instrumentos de ordenación de las actuaciones de transformación urbanística deberá incluir un informe o memoria de sostenibilidad económica, en el que se ponderará, en particular, el impacto de la actuación en las Haciendas Públicas afectadas por la implantación y el mantenimiento de las infraestructuras necesarias o la puesta en marcha y la prestación de los servicios resultantes, así como la suficiencia y adecuación del suelo destinado a usos productivos» (art.22.4). Se introduce de lleno la necesaria clarificación de la distinción entre los conceptos de "sostenibilidad económica" con el de la "Memoria de viabilidad económica" o "Estudio Económico-Financiero", y que aplicados a la operación urbanística que aquí se practica, se entienden como:

8 Real Decreto Legislativo 7/2015, de 30 de octubre, por el que se aprueba el texto refundido de la Ley de Suelo y rehabilitación Urbana. Aspecto este el de la sostenibilidad, que queda recogida y regulada en diversos artículos como son el correspondiente al referido artículo 3, el artículo 15, el artículo 17, el artículo 22, el artículo 24, el artículo 31 o la Disposición transitoria cuarta. Relativa a los Criterios mínimos de sostenibilidad, al igual que la ley del suelo que la precedía mostraría respecto a esta cuestión como « Si, trascurrido un año desde la entrada en vigor de la Ley 8/2007, de 28 de mayo, de Suelo, la legislación sobre ordenación territorial y urbanística no estableciera en qué casos el impacto de una actuación de urbanización obliga a ejercer de forma plena la potestad de ordenación, esta nueva ordenación o revisión será necesaria cuando la actuación conlleve, por sí misma o en unión de las aprobadas en los dos últimos años, un incremento superior al 20 por ciento de la población o de la superficie de suelo urbanizado del municipio o ámbito territorial». 
- Memoria o Informe de Sostenibilidad Económica, incardinada a la realización de «un análisis de la viabilidad económica tanto para los particulares instantes de la ejecución como para las Administraciones Públicas; y desde el punto de vista temporal, el horizonte considerado va más allá de la ejecución de la urbanización, ampliándose al análisis del coste público de mantenimiento y conservación de los nuevos ámbitos una vez urbanizados y recibidos por la Administración Pública, especialmente la Local»9.

- Memoria de Viabilidad Económica o Estudio Económico-Financiero, destinada a «evaluar la suficiencia de los recursos económicos para la ejecución material de todas las infraestructuras y servicios necesarios para la puesta en funcionamiento de la nueva pieza de la ciudad, sin merma de la calidad urbana anteriormente consolidada, siendo su objeto la cuantificación del coste de la actuación urbanística desde la perspectiva del instante de su ejecución ${ }^{10}$.

Demostrándose a través de la normativa al uso, como el proyecto Madrid Nuevo Norte, debe de encajarse y adaptarse e la finalidad de la sostenibilidad, que como se ha podido comprobar no solamente se delimita a tratar la vertiente podámoslo decir medioambiental, sino que también abarcaría a los aspectos sociales y económicos. En cumplimiento de este compromiso legalmente sustentado, la iniciativa urbanística que nos ocupa tiene que ser asimilado en la consideración de un proyecto sosteniblemente viable, que regenere (en términos urbanísticos), la zona norte de la ciudad de Madrid, permitiendo la reducción de los agentes dañinos y contaminantes del medio ambiente y a su vez haciendo posible que se reduzcan los consumos de los recursos naturales propiciando por ello una mayor eficiencia energética.

En definitiva, si descendemos a la Modificación del Plan General de Ordenación Urbana de Madrid, se observa claramente como este conduciría a una también "modificación" de la ordenación urbanística de aquellos suelos que a través de la materialización de una nueva propuesta, iban a quedar afectados por la misma, y que cuando dicho Plan puntualmente modificado fuera fruto de aplicación, se enfrentaría a la dificultad de intervenir sobre unos suelos urbanos que por su situación céntrica tildaban como de arduos y complejos, ya que en estos concurrirían un gran número de elementos e infraestructuras que iban a ser un factor condicionante de las determinaciones tendentes a la ordenación. La Modificación del Plan General de Ordenación Urbana de Madrid dispone la presencia

9 Modificación Puntual del PGOUM de 1997, en los ámbitos de Planeamiento: APR 08.03 "Prolongación de la Castellana” y APE 05.27 "Colonia Campamento". Para la Definición de las Determinaciones y Parámetros de Ordenación Urbanística "Madrid Nuevo Norte" (2018). Anexo 4. Informe de Sostenibilidad Económica y Estudio Económico Financiero. En: https://www-2.munimadrid.es/fsdescargas/VISAE_WEBPUB/NTI/1352018-00489/contenido_no_modificable/docsMaterializado/09024E4E800A358A_102\%204\%20Anexos\%20 Estudio\%20Viabilidad\%20Esconomica.pdf.

10 Modificación Puntual del PGOUM de 1997, en los ámbitos de Planeamiento: APR 08.03 "Prolongación de la Castellana” y APE 05.27 “Colonia Campamento". Para la Definición de las Determinaciones y Parámetros de Ordenación Urbanística "Madrid Nuevo Norte" (2018). Anexo 4. Informe de Sostenibilidad Económica y Estudio Económico Financiero. En: https://www-2.munimadrid.es/fsdescargas/VISAE_WEBPUB/NTI/1352018-00489/contenido_no_modificable/docsMaterializado/09024E4E800A358A_102\%204\%20Anexos\%20 Estudio\%20Viabilidad\%20Esconomica.pdf. 
de unas Áreas de Planeamiento Específico, en concreto las tres áreas correspondientes con los APE, estos son los referidos a Centro de Negocios Chamartín, al Malmea - San Roque - Tres Olivos, y a la zona al Oeste del barrio de las Tablas. Además de un Área de Planeamiento Remitido, concerniente con la denominada APR, es decir con la vinculada a la Estación de Chamartín. El Plan General en consecuencia diferencia por un lado las áreas del APE, comprendiendo a este respecto dentro de una ordenación pormenorizada y específica de su superficie. De aquellas otras Áreas de planeamiento referentes al APE, para el que dicho Plan General se atiene aquella a la existencia de un instrumento de planeamiento que desarrolle y particularice el conjunto de los objetivos remarcados por dicho instrumento ${ }^{11}$.

\section{RESULTADOS}

La aplicación de la metodología señalada en la presente investigación pone de manifiesto la necesidad de actuar en un territorio en el que la realidad generada por una diacronía en la que los procesos desencadenados por las actuaciones desarrolladas sobre el territorio, marcan la vida de un espacio, en no pocos casos, degradado, y en el que el tercer paisaje lo integran espacio residuales, cuya recuperación, amén de necesitar de decisiones "políticas", pueden encontrar en las actividades turísticas "postcovid", una situación que en los momentos actuales no podemos ni debemos dejar de estudiar. De hecho, como meros elementos constituyentes del progreso y el crecimiento económico, se erigen las infraestructuras viarias que vertebran el territorio de Madrid, y lo conexionan con el resto del territorio español. Meros "residuos" del conjunto de actividades económicas, la red ferroviaria y sus catenarias, se ven complementadas con carteles publicitarios que siembran espacios baldíos, colmados de vegetación residual, que se hacen paso en el que hacer de la expansión de una gran ciudad (ver figura $\mathrm{n}^{\circ} 6$ ).

11 Modificación Puntual del PGOUM de 1997, en los ámbitos de Planeamiento: APR 08.03 "Prolongación de la Castellana" y APE 05.27 "Colonia Campamento". Para la Definición de las Determinaciones y Parámetros de Ordenación Urbanística "Madrid Nuevo Norte" (2018). Anexo 4. Informe de Sostenibilidad Económica y Estudio Económico Financiero. 


\section{Figura $n^{0} 6$ \\ EL TERCER PAISAJE DE LAS INFRAESTRUCTURAS FERROVIARIAS}

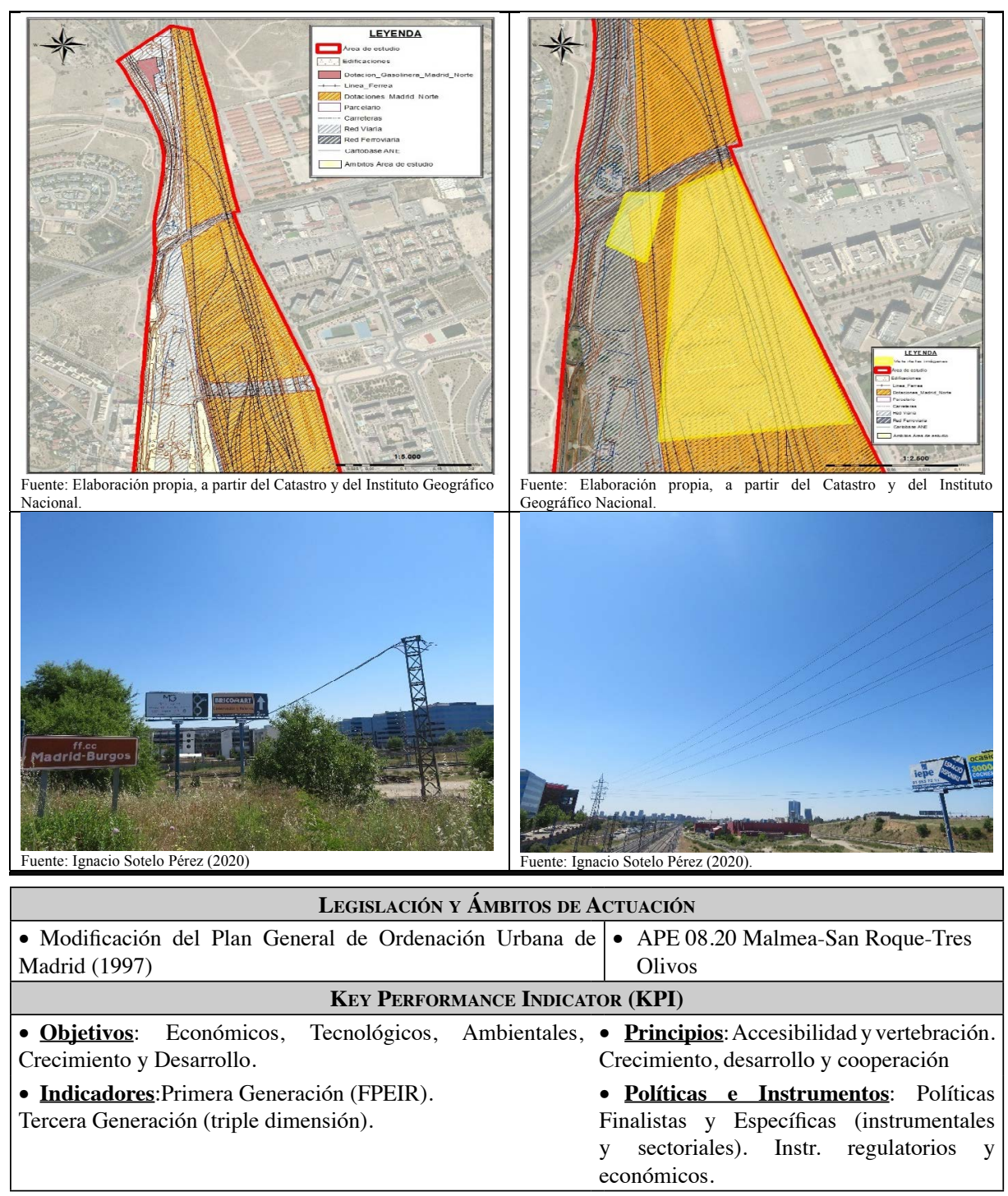

De hecho, marcados por el aparente aislamiento (sin apenas protección ante el acceso incontrolado), los túneles y viaductos evolucionan raudamente a la configuración de espacios sombra ("shadowed places"), en los que, a pesar de su funcionalidad, utilidad e importancia, se nos muestran como lugares marginales, en los que los que, el denominado "arte callejero" colma sus paredes y los vagones - hoy en desuso-, dando cuenta de lo 
atractivo de un espacio, en apariencia, estático. A lo lejos, la ciudad se muestra ajena a una realidad palpable, desconocida, desconcertante,..., de la que solo unos pocos perciben, conocen $\mathrm{y}$, sobre todo, valoran (ver figura $\mathrm{n}^{\circ} 7$ ).

\section{Figura $\mathbf{n}^{0} 7$ \\ VÍAS Y VIADUCTOS: CAMINOS URBANOS HACIA EL TERCER PAISAJE}

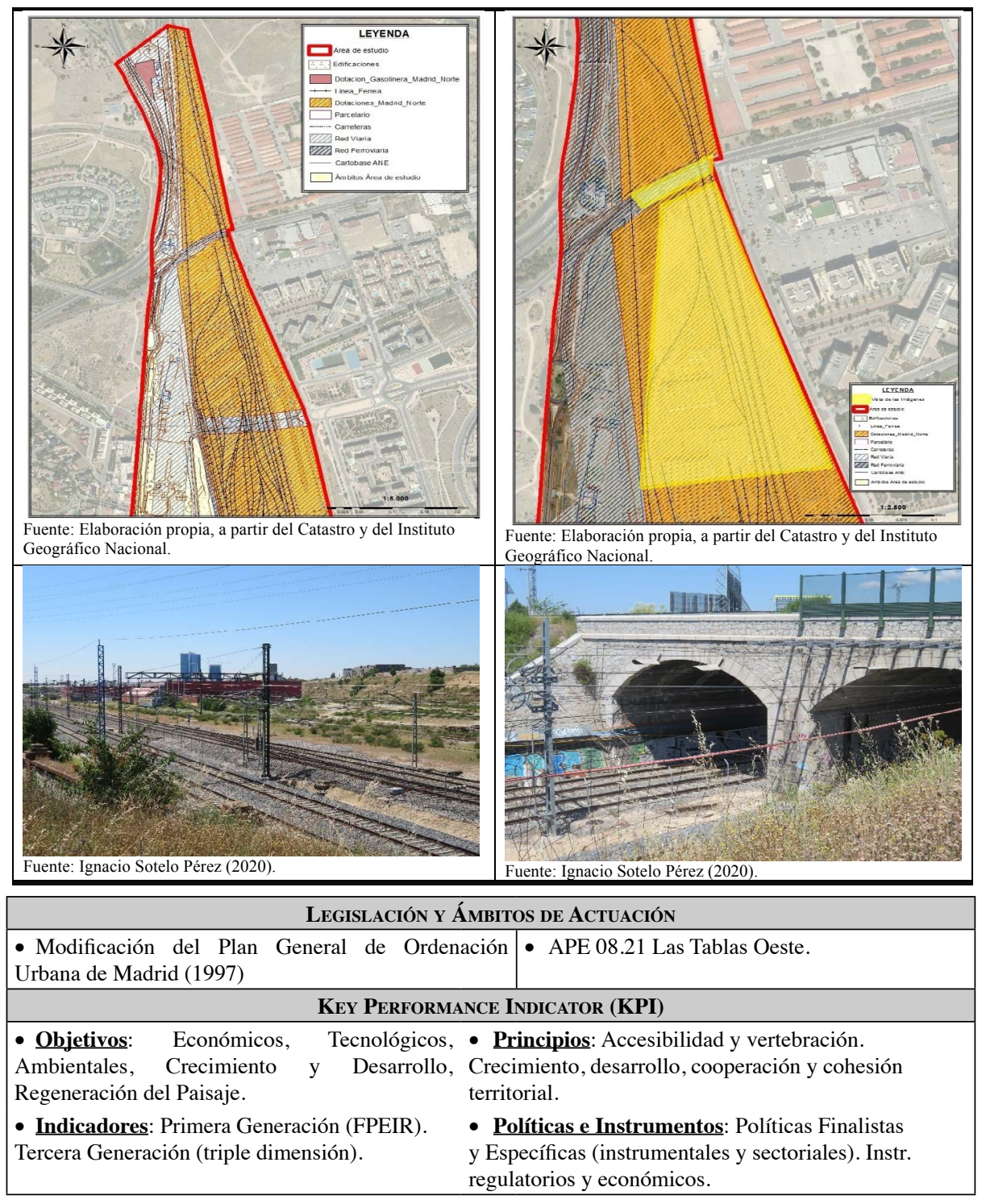


Lo anteriormente señalado, se concreta al tratar de los vestigios del pasado que se pueden admirar desde el viaducto que sobrevuela las vías del tren; nexo de unión entre una ciudad que se expande y crece "negando el lugar" ("nonplaceurbanrealm"), se observan elementos diversos constituyendo un paisaje sin paisanaje. Paneles publicitarios crecen a la sombra de las catenarias; muros de protección, que prohíben el paso, se vislumbran marcados por graffitis, tagging y throw ups, vías de trenes en cuyos márgenes se acumulan restos rieles, traviesas, escarpias y balastro, que descansan viendo el paso del tiempo, pequeños matorrales y maleza se apresura a tupir el suelo arenoso de verdes colores,..., mientras la vida sigue para los viajeros, trabajadores y estudiantes de la Escuela de Aplicación y Tiro de Infantería (ver figura $\mathrm{n}^{\circ}$ 8). Todo ello, configurando un Tercer Paisaje en un espacio funcional, actual, necesario para el desarrollo de actividades económicas y sociales, vivido y transitado, en el que las nuevas actividades turísticas deben jugar un papel principal.

Serpenteantes, los trenes parecen deslizarse entre una maraña de malas hierbas que proliferan sin control, tan solo limitadas por el crecimiento de las vías férreas. Restos de botellas, papeles, plásticos,..., en definitiva, basura, marcan un camino de libre entrada a la superestructura viaria, en la que se suceden trenes que transcurren ajenos a la pobreza y degradación de un terreno baldío. En el campo sembrado de asfalto, se erige aislada la estación de cercanías de Fuencarral, en las que el transcurso del tiempo parece detenerse (figura $\mathrm{n}^{\circ}$ 9).

Paradojas que marcan la lógica de un espacio residual, hoy degradado y desconocido para los habitantes de una gran urbe como Madrid, encontramos los restos desatendidos, en venta u ocupados, de edificios que, en otro tiempo, cosechaban dinamismo, empleo y trabajo. Ayer marcadas por el apogeo de crecimiento y riqueza, las fábricas de pinturas, materiales de construcción, talleres, e, incluso empresas de alta innovación tecnológica dedicadas a la construcción como Dragados, hoy ven como sus edificios son devorados por el aislamiento y abandono de un espacio secundario, a la espera de otros tiempos, en el que la Covid-19 y las actividades turísticas no han desempeñado un papel destacado, y, que, sin embargo, pueden y deben ser una posible solución a los problemas que actualmente se plantean (figura $\mathrm{n}^{\mathrm{o}} 10$ ).

Muestra de la fragmentación urbana, al albor de las vías del tren, entre edificios de diversa índole, nexo de unión entre la ciudad de Madrid y el barrio dormitorio de Valverde, surgen espacios complejos, fruto del planeamiento urbanístico. Estos espacios nos dan habida cuenta de otras realidades urbanas, en las que el chabolismo y las ocupaciones ilegales siembran terrenos a la espera de nuevos usos (figura $\mathrm{n}^{\circ} 11$ ). Caminos de arena convergen con carreteras asfaltadas, dando unión a un espacio desunido, entre el orden y el caos, el progreso y el retroceso, la urbe y suburbio, el gobierno y el desgobierno.

Consecuencia de los procesos de expansión de la ciudad de Madrid, surgen espacios divergentes en los que antiguas construcciones primigenias, de una planta, se ven devoradas por edificaciones de mayor altura que se agolpan unos con otros, dejando espacios vacíos a la espera del lucro urbanístico. Lugares cuya estética dan cuenta de la falta de proporcionalidad ante la heterogeneidad del territorio y marcan nuevas jerarquías de poder que dimanan del propio ordenamiento urbanístico (figura $\mathrm{n}^{\mathrm{o}} 12$ ). 


\section{Figura $\mathbf{n}^{0} 8$}

\section{GENERANDO "TIERS PAYSAGES"}

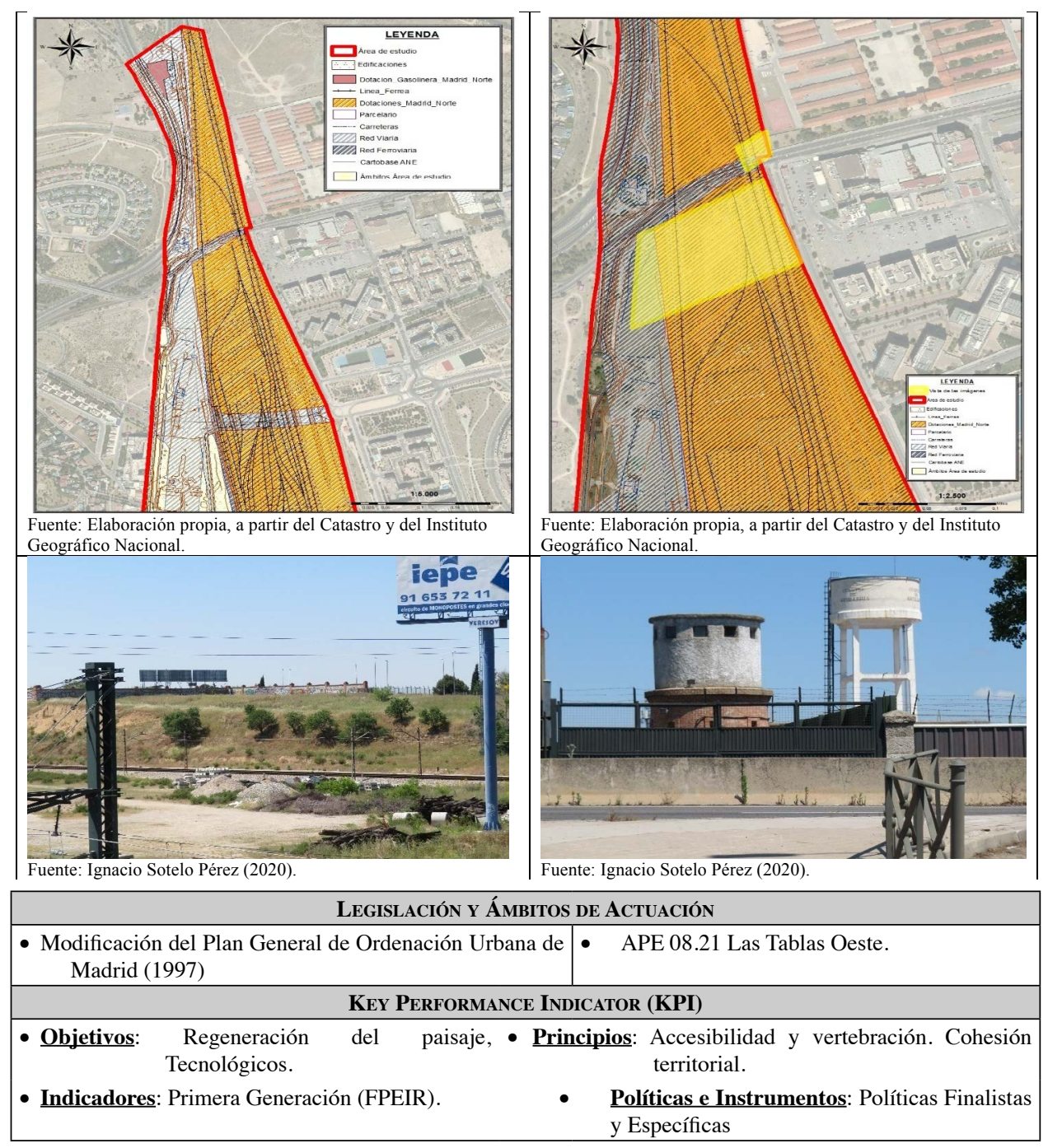




\section{Figura $\mathbf{n}^{0} 9$ \\ MADRID NUEVO NORTE Y SUS NO-LUGARES}

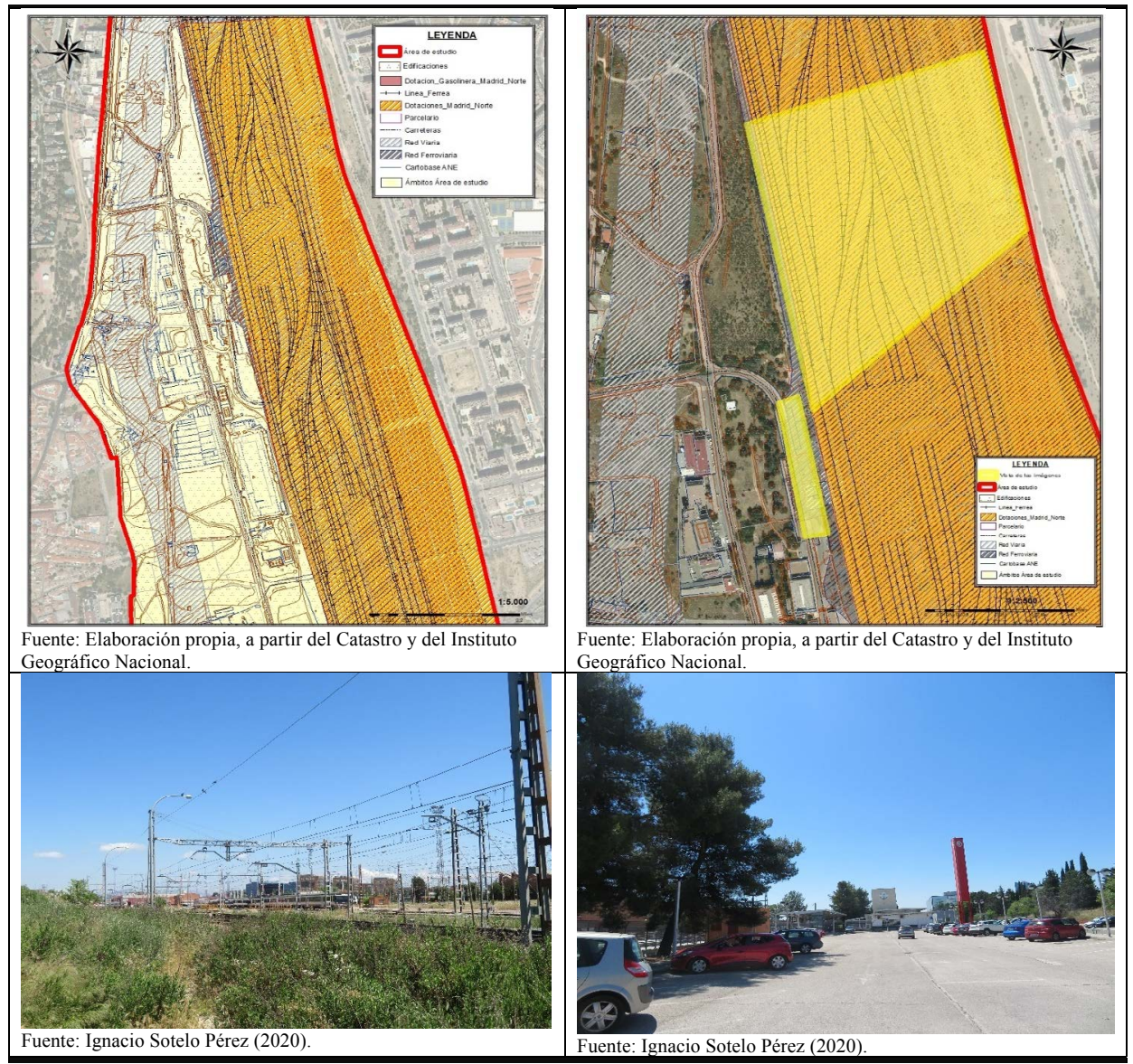

LEGISLACIÓN Y ÁMBITOS dE ACTUACIÓN

- Modificación del Plan General de Ordenación Urbana de Madrid • APE 08.20 Malmea-San Roque-Tres (1997)

Key Performance Indicator (KPI)

- Objetivos: Económicos, Tecnológicos, Sociales, - Principios: Accesibilidad y vertebración. Ambientales, Crecimiento y Desarrollo, Sociales, Institucionales.

Crecimiento, desarrollo y cooperación, Competitividad y cohesión.

- Indicadores: Primera Generación (FPEIR).

Tercera Generación (triple dimensión).

- Políticas e Instrumentos: Políticas Finalistas y Específicas (instrumentales $\mathrm{y}$ sectoriales). Instr. regulatorios y económicos. 


\section{Figura $\mathbf{n}^{0} 10$ \\ EL OLVIDO DE LA HISTORIA: EDIFICACIONES SIN USO}

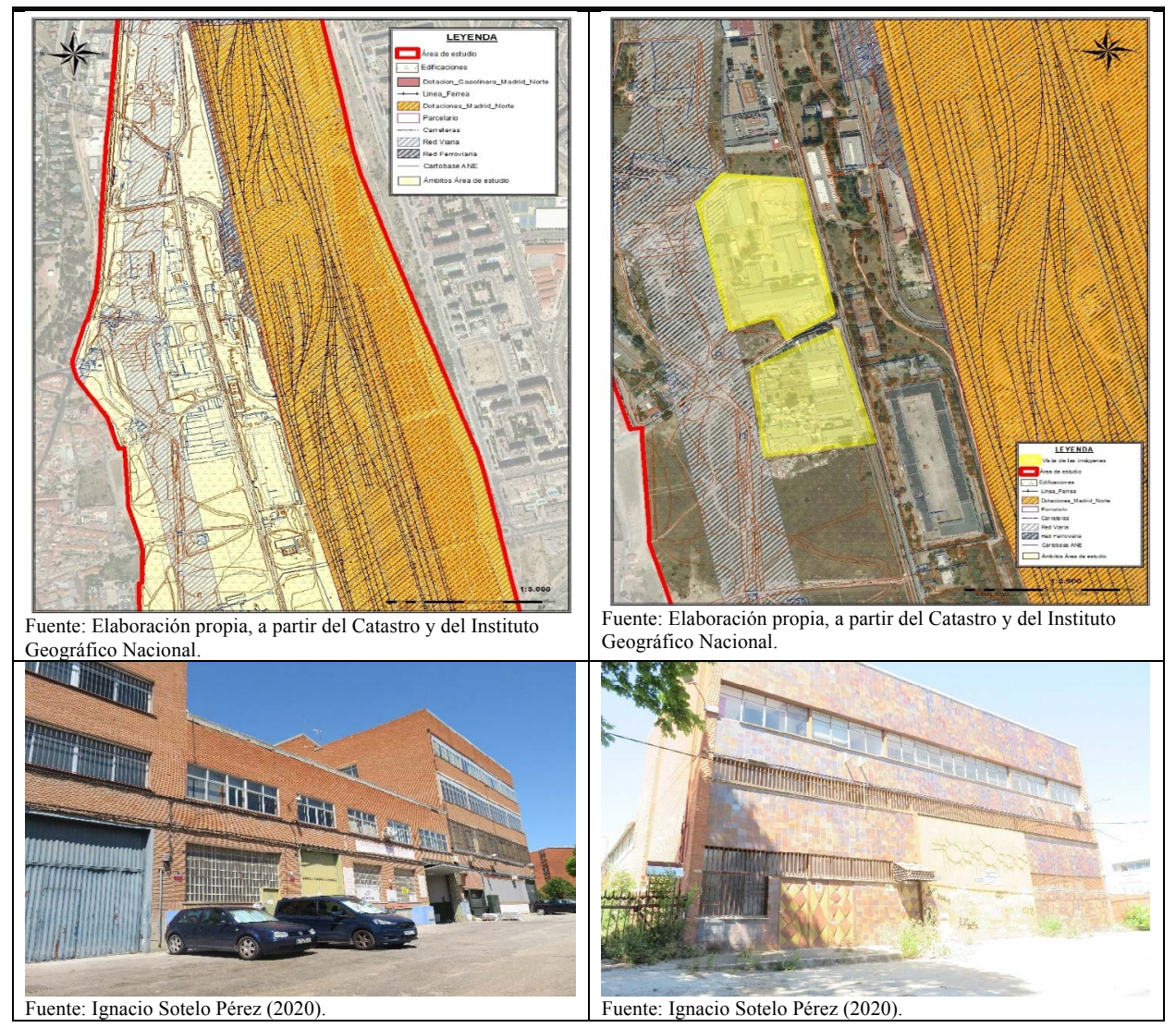

\begin{tabular}{|c|c|c|}
\hline \multicolumn{3}{|c|}{ LEGISLACión y Ámbitos de ACTUACIón } \\
\hline - Modificación del Plan General de Ordenación Urbana de Madrid (1 & 97) & $\begin{array}{l}\text { - APE 08.20 Malmea-San } \\
\text { Roque-Tres Olivos }\end{array}$ \\
\hline \multicolumn{3}{|c|}{ Key Performance Indicator (KPI) } \\
\hline 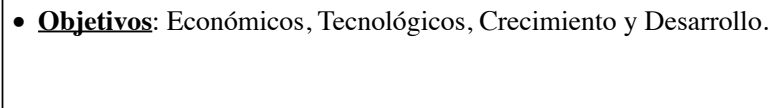 & - $\frac{\mathbf{P}}{\mathrm{co}}$ & $\begin{array}{l}\text { cipios: Crecimiento, } \\
\text { peración, cohesión y } \\
\text { petitividad. }\end{array}$ \\
\hline 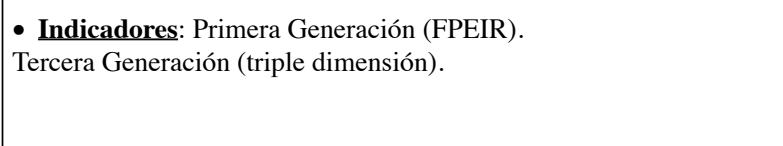 & $\begin{array}{l}-\frac{\mathbf{P}}{\mathrm{Pc}} \\
\text { (ir } \\
\text { re }\end{array}$ & $\begin{array}{l}\text { iticas e Instrumentos: } \\
\text { ticas Finalistas y Específicas } \\
\text { trumentales y sectoriales). Instr. } \\
\text { latorios y económicos. }\end{array}$ \\
\hline
\end{tabular}




\section{Figura $\mathbf{n}^{\circ} 11$}

\section{MADRID NUEVO NORTE: TRANSFORMANDOS LOS "SLOAP"}

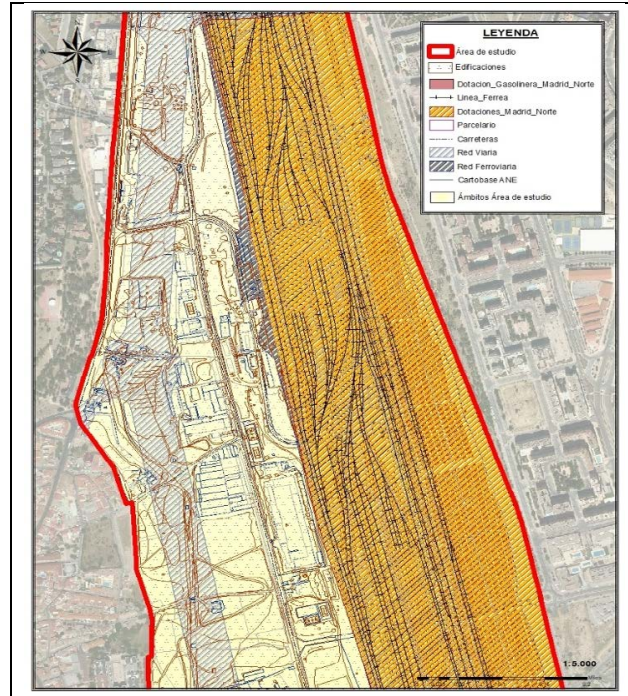

Fuente: Elaboración propia, a partir del Catastro y del Instituto Geográfico Nacional.

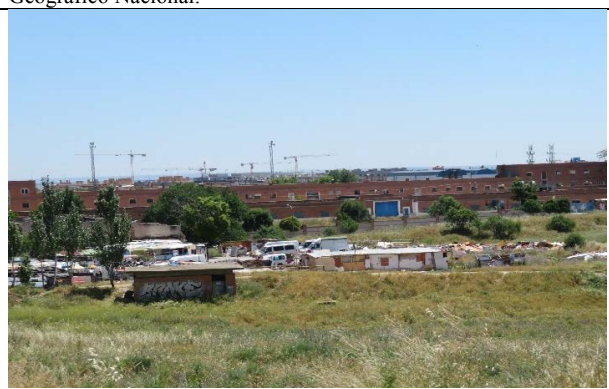

Fuente: Ignacio Sotelo Pérez (2020).

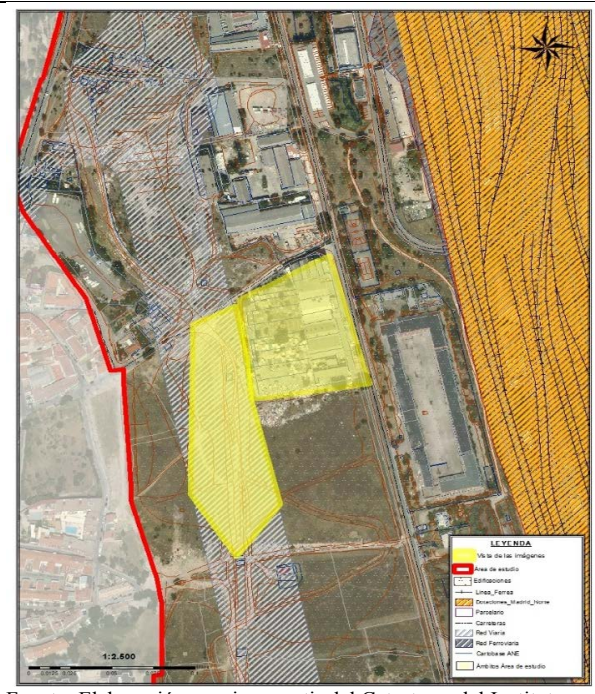

Fuente: Elaboración propia, a partir del Catastro y del Instituto Geográfico Nacional.

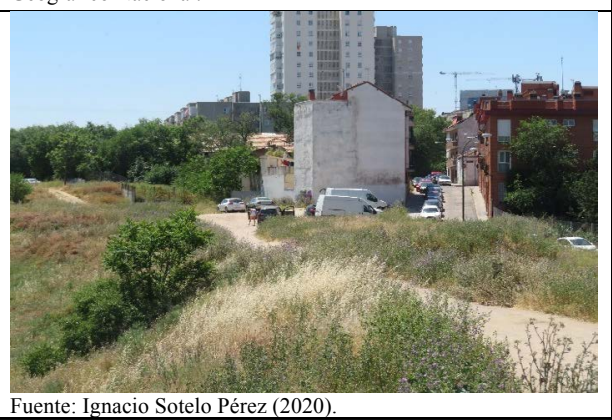

LEgISLACIÓn y Ámbitos de ACTUACIón

- Modificación del Plan General de Ordenación Urbana de Madrid • APE 08.20 Malmea-San Roque(1997) Tres Olivos

Key Performance Indicator (KPI)

- Objetivos: Económicos, Ambientales, Sociales, Regeneración del • Paisaje, Crecimiento y Desarrollo.

- Indicadores: Primera Generación (FPEIR).

Principios: Crecimiento, desarrollo, competitividad y cohesión.

Tercera Generación (triple dimensión).

- Políticas e Instrumentos:

Políticas Finalistas y Específicas (instrumentales y sectoriales). Instr. regulatorios y económicos. 


\section{Figura $\mathbf{n}^{0} 12$ \\ EL LUCRO DEL TERCER PAISAJE}

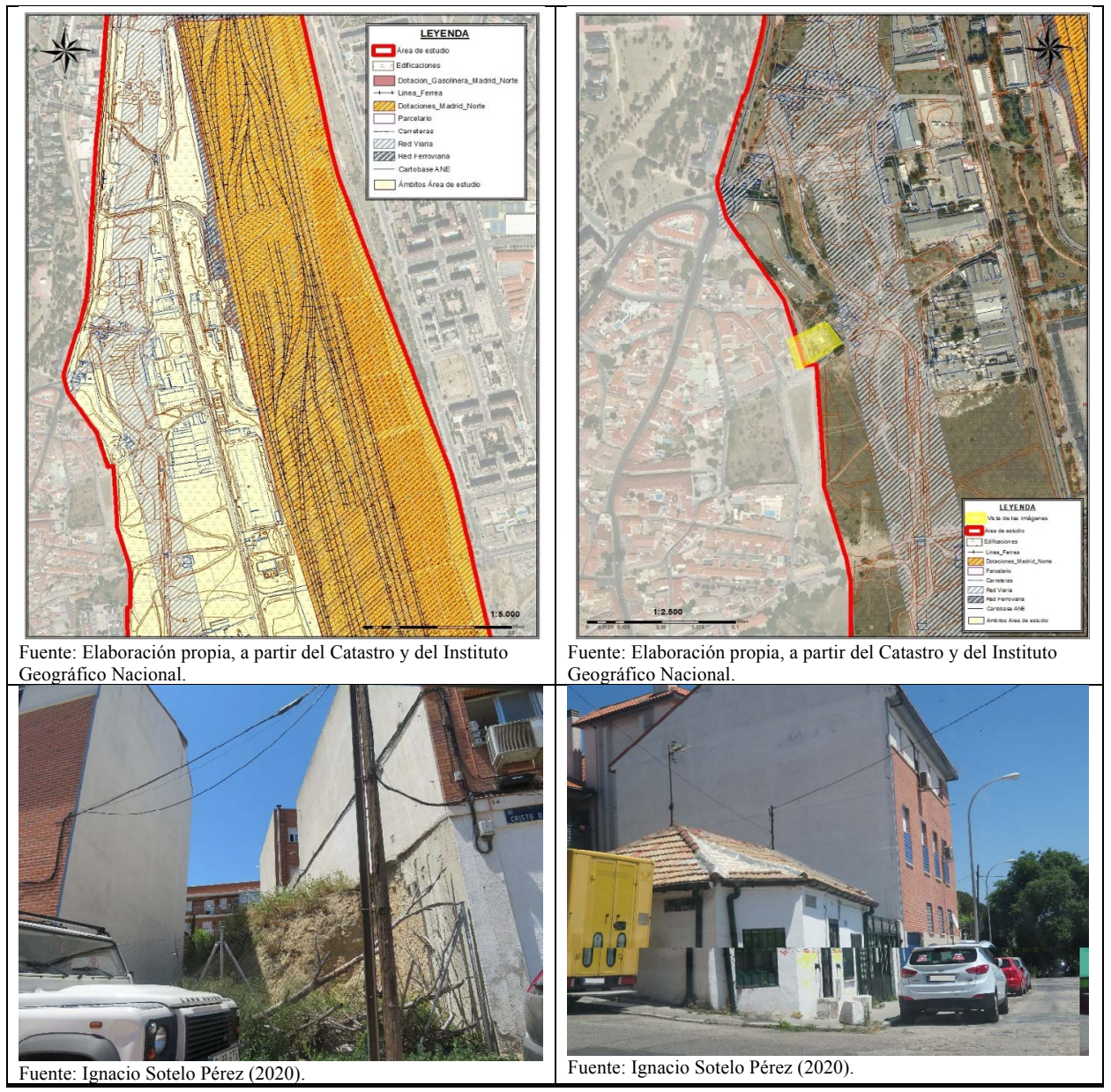

LEgisLaCión y Ámbitos de ACTUACIón

- Modificación del Plan General de Ordenación Urbana • APE 08.20 Malmea-San Roque-Tres Olivos de Madrid (1997)

\section{Key Performance Indicator (KPI)}

- Objetivos: Económicos, Sociales, Crecimiento y Desarrollo.

- Indicadores: Primera Generación (FPEIR). Tercera Generación (triple dimensión).
- Principios: Crecimiento, desarrollo y competitividad.

- Políticas e Instrumentos: Políticas Finalistas y Políticas instrumentales. Instr. regulatorios y económicos. 
Vestigios de un pasado aún cercano, encontramos grandes descampados, sembrados de malas hierbas, en los que contrastan edificaciones de diversa índole y naturaleza. La ermita de San Roque muestra una clara dicotomía entre espacios planificados - marcados por edificios de nueva construcción, en los que las obras continúan siendo una constante- $-y$, terrenos aislados, marginados, en los que las casas bajas y chabolismo continúa siendo una parte más de este Tercer Paisaje en transformación, claramente definido en los preceptos del "Space Left Over after Planning" (ver figura n ${ }^{\circ} 13$ ).

Marcando fronteras, sobre el camino de asfalto que discurre al margen de las vías del tren, se perciben espacios residuales que muestran la dicotomía entre lugares que, como elementos "vertebradores" del territorio, muestran dinamismo económico y social, y terrenos baldíos, residuales, abandonados, o definidos por actividades secundarias. Sobre los yermos campos de cultivo, de un pasado no tan lejano, que sucumbieron a los cambios de usos del suelo, a la expansión de la urbe, a la degradación del espacio, se percibe la degradación del entorno; la ermita se San Roque nos dibuja el horizonte, chabolas que siembran terrenos vacíos, vallas derrumbadas que muestran el desprecio por la propiedad privada, muros y bloques de contención de hormigón sirven de lienzo al spray, garitas destrozadas porque ya no son de utilidad - la tecnología ha sustituido sus funciones,$- \ldots$ configuran un paisaje complejo de describir, difícil de atravesar, lugares inacabados a la espera de un futuro, cuanto menos, diferente (figura $\mathrm{n}^{\circ} 14$ ).

Marcando la dicotomía entre los "no lugares" y las viviendas que surgen de los procesos de transformación de los denominados "poblados de absorción" (antes de 1950 pueblo de Fuencarral, hoy convertido en el barrio de Fuencarral-Valverde), consecuencia del proceso forzosos de abandono de las tierras de cultivo y de una falta de planificación socioeconómica, se agolpan sin orden alguno viviendas, carreteras, vías férreas y empresas dedicadas a la fabricación de cemento y hormigón. La localización de las fábricas de diversa índole, se propagan a saltos en los márgenes de los caminos, hoy convertidos en carreteras asfaltadas (figura $\mathrm{n}^{\circ} 15$ ).

Los paisajes residuales que configuran el Tercer Paisaje son visible ejemplo de los cambios sociales, económicos, políticos,... de una ciudad en continua evolución, como es Madrid. En las propias instalaciones de red ferroviaria la ocupación ilegal y el chabolismo asaltan infraestructuras de notable relevancia, provocando su degradación y la de su entorno. La falta de planeamiento y los cambios no regulados de los procesos de industriales y empresariales llevan parejo el aislamiento de fábricas de hormigón y cemento, el abandono de edificios de oficinas, o, incluso, la separación de espacios urbanos colindantes (figura $\mathrm{n}^{\mathrm{o}} 16$ ).

Consecuencia de los procesos de vertebración territorial, a través de la construcción de no lugares, surgen espacios marginales, secundarios, contiguos que, a pesar de su proximidad, se nos presentan lejanos, aislados, imperceptibles. Su valor paisajístico viene marcado por su uso de escombreras en los que erigir carteles publicitarios que desvían la mira de la degradación, dando lugar a "wastelandscape" En apariencia inexistentes, se nos muestran inaccesibles, convirtiéndolos en despojos urbanos a la merced del mercado (figura $\mathrm{n}^{\circ} 17$ ). 


\section{Figura n⿳0 13 \\ “SPACE LEFT OVER AFTER PLANNING” EN MADRID NUEVO NORTE}

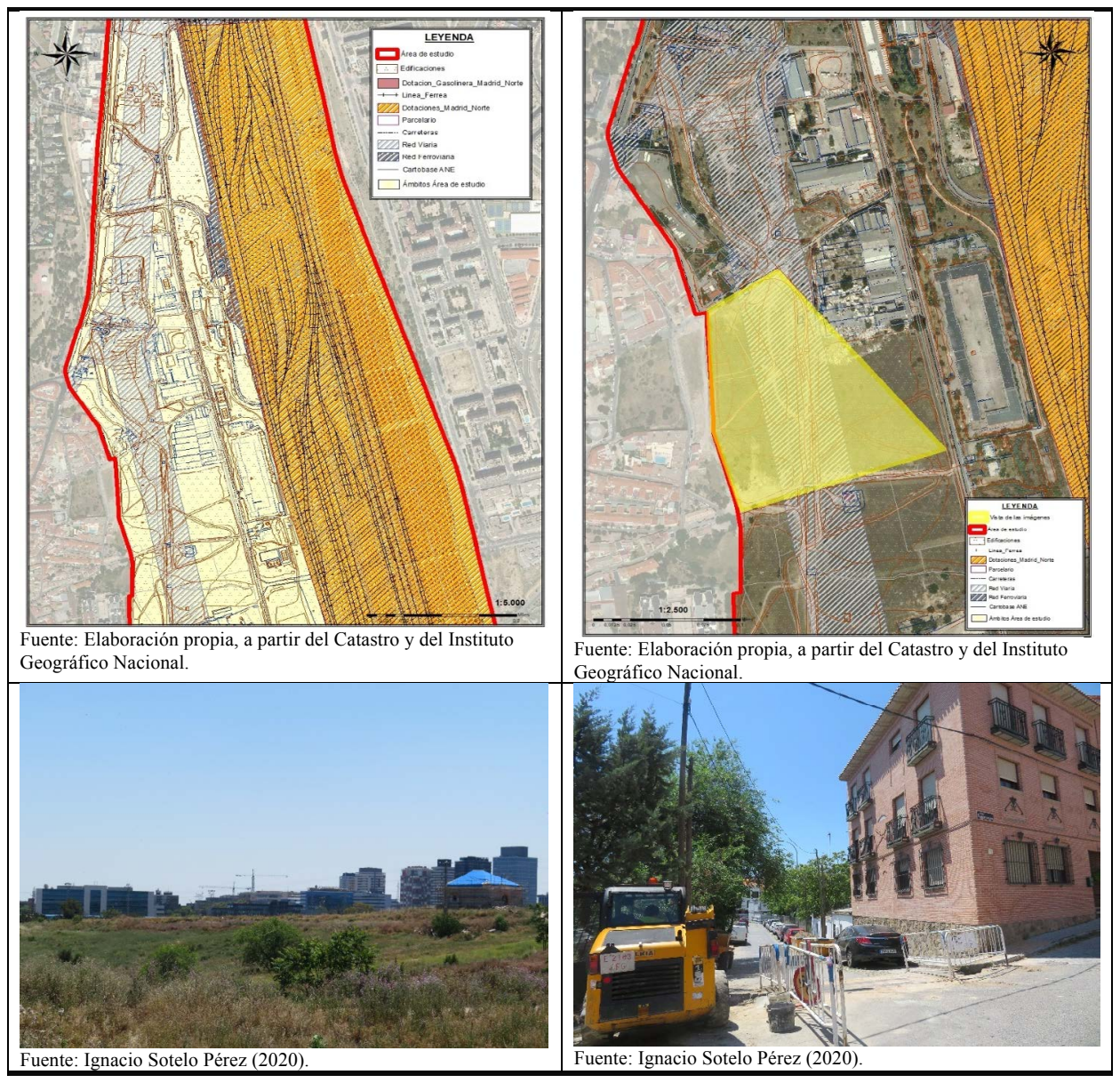

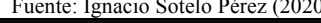

Legislación y Ámbitos de ACtuación

- Modificación del Plan General de Ordenación Urbana de Madrid (1997)

- APE 08.20 Malmea-San Roque-Tres Olivos

\section{Key Performance Indicator (KPI)}

- Objetivos: Económicos, Ambientales, Sociales, Regeneración del Paisaje, • Principios: $\quad$ Crecimiento, Crecimiento y Desarrollo.

- Indicadores: Primera Generación (FPEIR). Tercera Generación (triple dimensión). desarrollo, competitividad y cohesión.

- Políticas e Instrumentos: Políticas Finalistas y Específicas (instrumentales y sectoriales). Instr. regulatorios y económicos. 


\section{Figura $n^{0} 14$ \\ LAS NATURALEZAS INTERMEDIAS DE MADRID NUEVO NORTE}

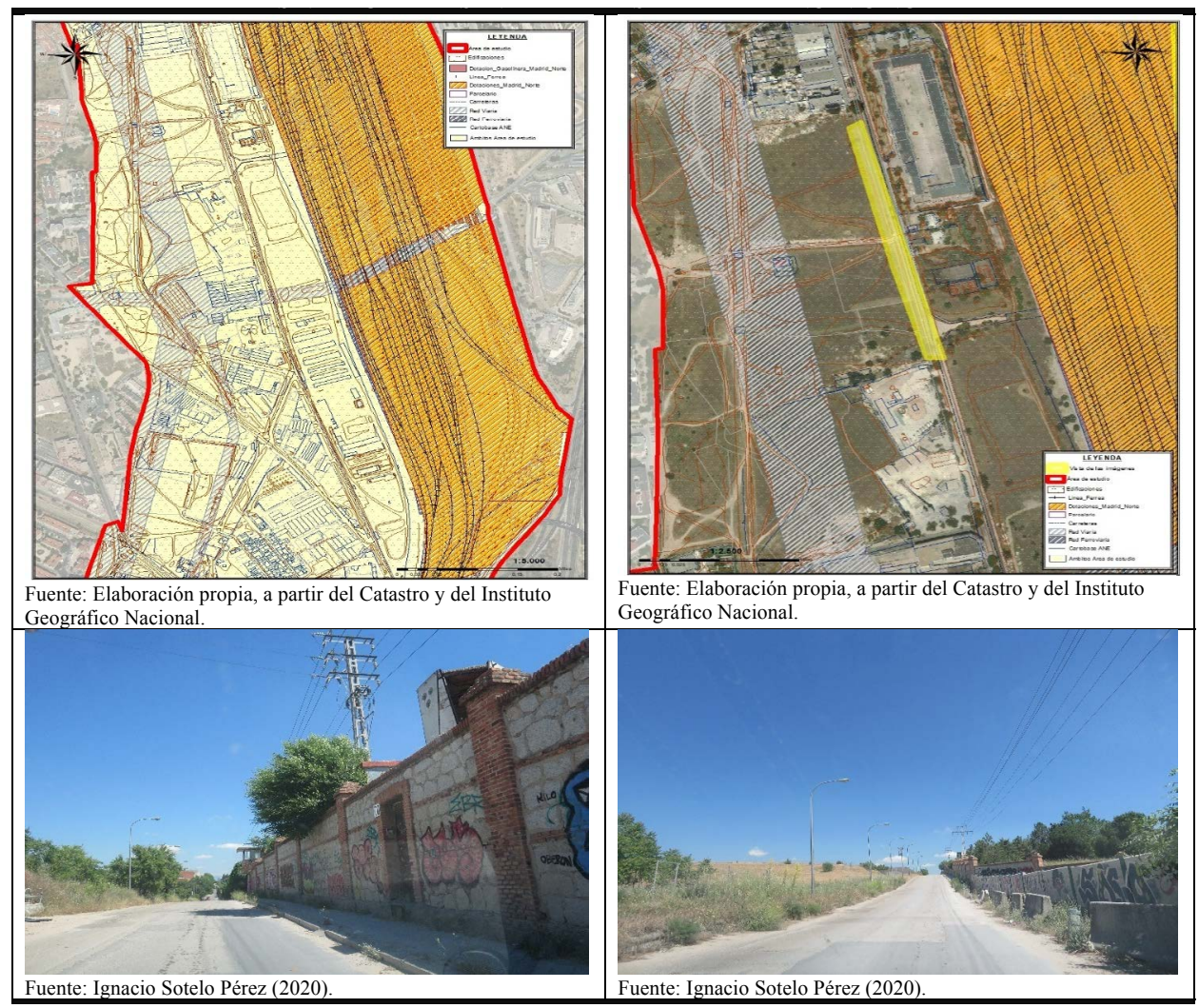

Legislación y Ámbitos de ACTUACión

- Modificación del Plan General de Ordenación Urbana de Madrid (1997)

- APE 08.20 Malmea-San Roque-Tres Olivos

Key Performance Indicator (KPI)

- Objetivos: Regeneración del paisaje, Crecimiento y Desarrollo.

- Indicadores: Primera Generación (FPEIR).

Tercera Generación (triple dimensión).
- Principios:

Accesibilidad, vertebración y cohesión territorial.

- Políticas e Instrumentos: Políticas Finalistas y Específicas (instrumentales y sectoriales). Instr. regulatorios y económicos. 


\section{Figura $\mathbf{n}^{0} 15$ \\ MADRID NUEVO NORTE: EXTRACCIÓN EN DECONSTRUCCIÓN}

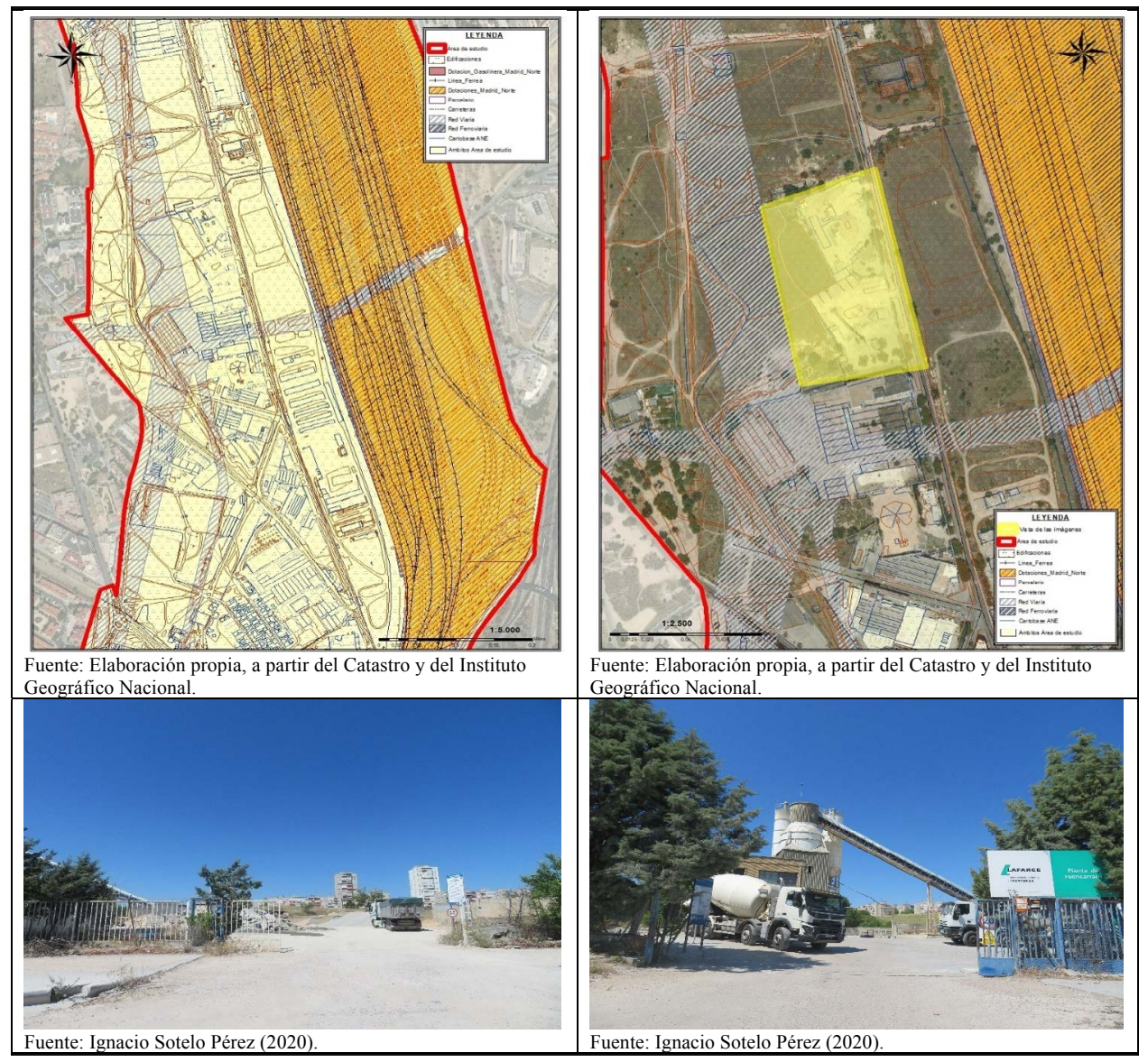

LEGISLACIÓN Y ÁMBITOS DE ACTUACIÓN

- Modificación del Plan General de Ordenación Urbana de • APE 08.20 Malmea-San Roque-Tres Olivos Madrid (1997)

\section{Key Performance Indicator (KPI)}

- Objetivos: Económicos, Tecnológicos, Ambientales, - Principios: Competitividad, cohesión,

Crecimiento y Desarrollo.

- Indicadores: Primera Generación (FPEIR).

Tercera Generación (triple dimensión).
Crecimiento, desarrollo y cooperación

- Políticas e Instrumentos: Políticas Finalistas y Específicas (instrumentales y sectoriales). Instr. regulatorios y económicos. 


\section{Figura $n^{0} 16$ \\ PAISAJES RESIDUALES DE MADRID NUEVO NORTE}

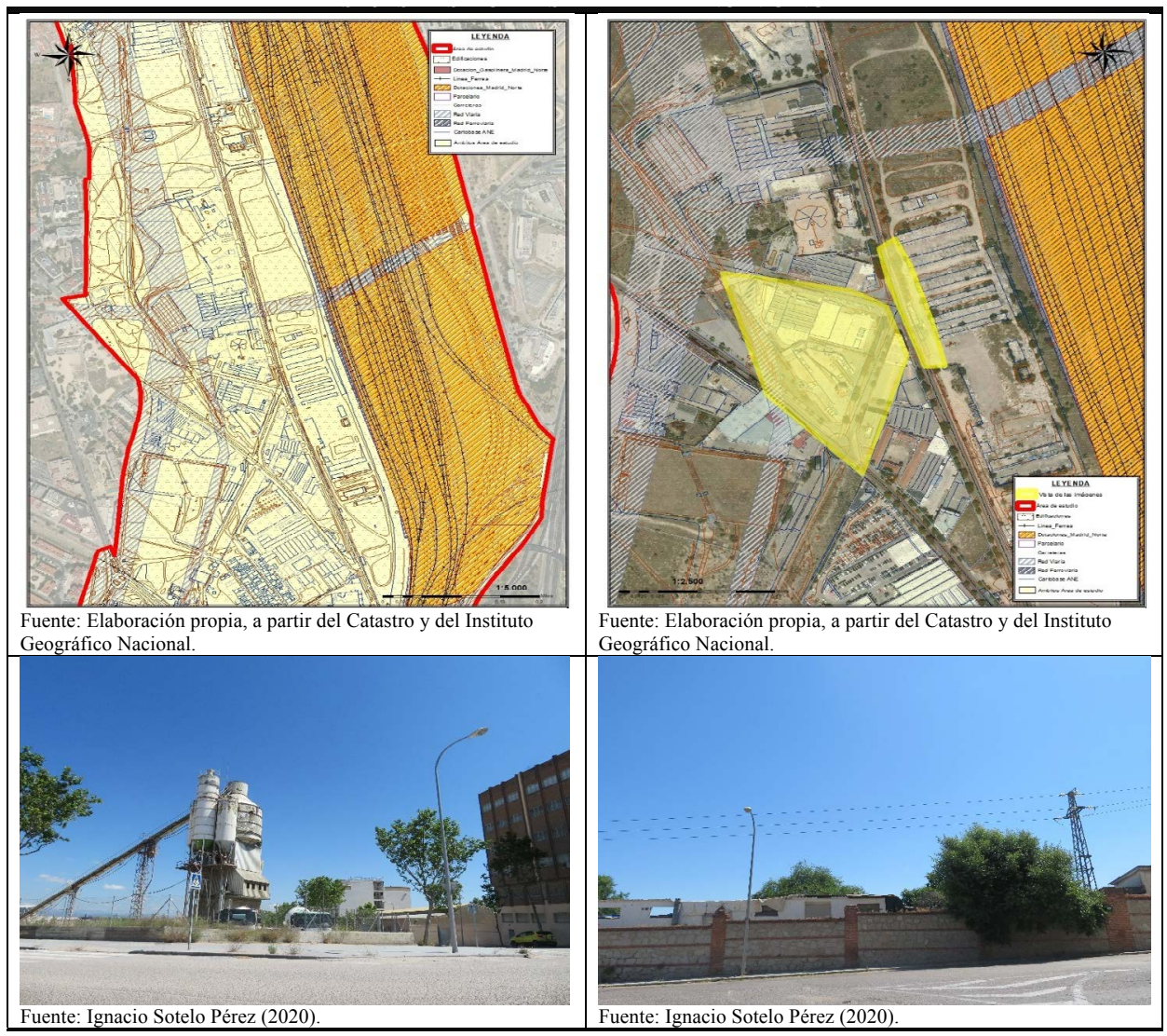

Legislación y Ámbitos de ACtUACión

- Modificación del Plan General de Ordenación Urbana de • APE 08.20 Malmea-San Roque-Tres Madrid (1997) Olivos

\section{Key Performance Indicator (KPI)}

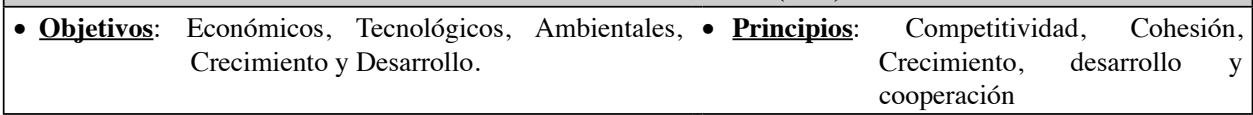




\section{FIGURA n 17 \\ EL CARÁCTER DEL TERCER PAISAJE}

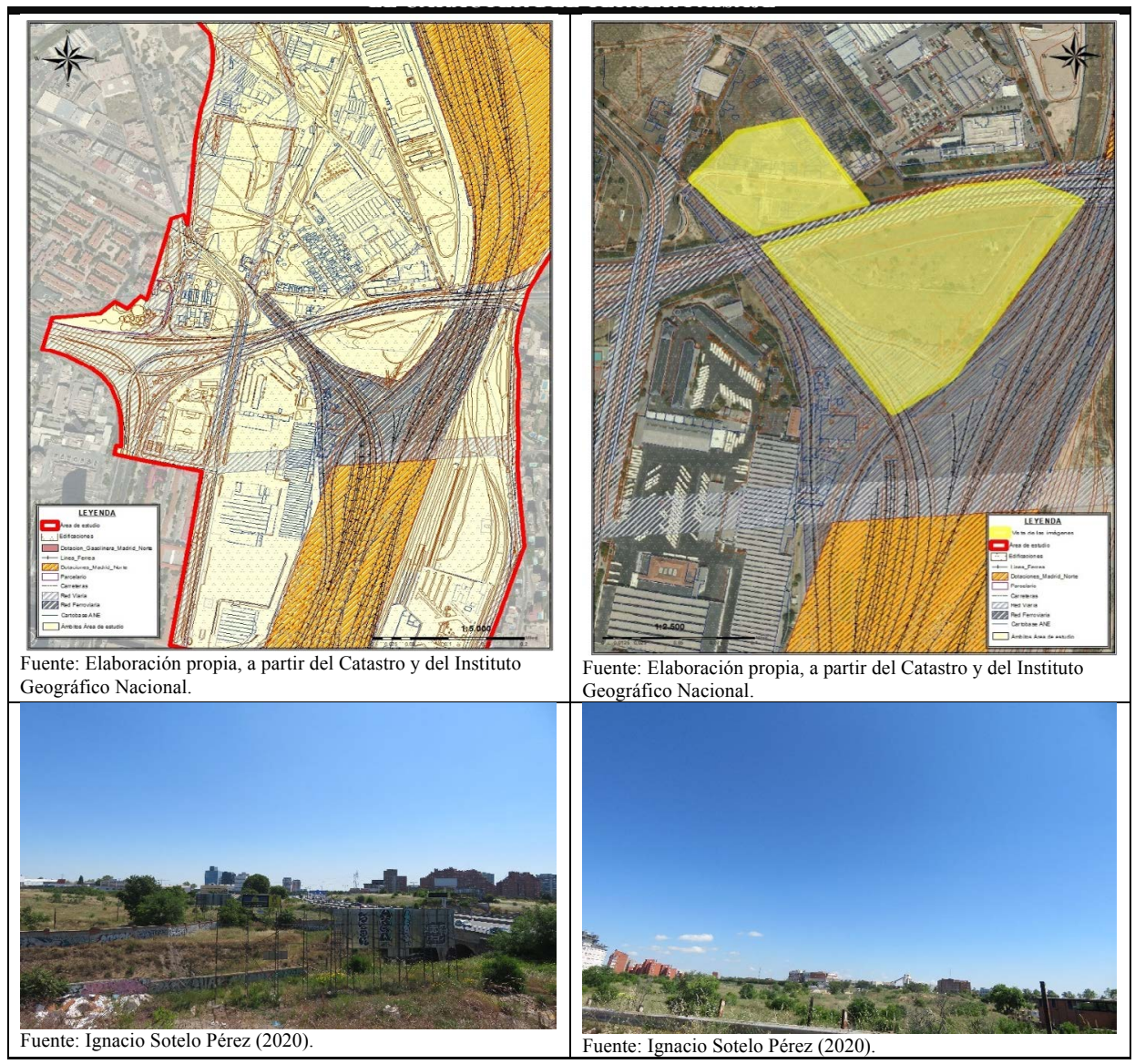

LEGISLACión y ÁMbitos de ACTUACión

- Modificación del Plan General de Ordenación Urbana de Madrid (1997)

- APE 08.20 Malmea-San Roque-Tres Olivos

Key Performance Indicator (KPI)

- Objetivos: Económicos, Tecnológicos, Ambientales, - Principios: Accesibilidad y vertebración. Crecimiento y Desarrollo y Regeneración del Paisaje. Crecimiento, desarrollo y cooperación, Cohesión territorial y competitividad.

- Indicadores: Primera Generación (FPEIR). Tercera Generación (triple dimensión).
- Políticas e Instrumentos: Políticas Finalistas y Específicas (instrumentales $\mathrm{y}$ sectoriales). Instr. regulatorios $\mathrm{y}$ económicos. 
Áreas marginadas, consecuencia de los procesos de intervención y planificación, se despliegan por el territorio, mostrando espacios que, sin estar aislados, presentan situaciones de postergación. La falta de un uso actual directo, convierten la estética de estos lugares en vertederos y estercoleros en los que Tiriricas, gramíneas, Sorghum halepense, entre otras especies, siembran los descampados, convirtiéndolos en espacios en sombra. Construcciones en desuso, paneles comerciales que emergen de la tierra, caminos aislados, donde el alumbrado brilla por su ausencia, hacen de estos espacios, lugares residuales se surgen espontáneamente en medio de la urbe (figura $\mathrm{n}^{\circ} 18$ ).

En 1948 daban comienzo las obras de edificación de las "viviendas colectivas" de la Colonia San Cristóbal, frente a las cocheras de la EMT. Más de 70 años después, aquellas viviendas que emulaban tranquilidad, aislamiento y recogimiento, en medio del campo, marcan una nueva realidad territorial que dista de la del pasado. Absorbidas por la ciudad, dominadas por el continuo tránsito de vehículos que ejercen una sustancial presión sobre el medio, marcadas por la presión urbanística y los intentos de gentrificación (ver figura $\mathrm{n}^{\mathrm{o}}$ 19). Claramente, nos encontramos ante un lugar fuera de lugar, reminiscencia de un pasado atrapado por el presente $\mathrm{y}$, en apariencia, arrasado por el futuro.

Lugar de desorden en un espacio de "orden". Los procesos de reconversión y, por ende, de recalificación de los suelos limítrofes a la estación de Chamartín, nos hacen eco de una constreñida dualidad entre aquellos terrenos que encontraron un nuevo uso y otros que se disiparon entre el asfalto. Terrenos baldíos a la espera de un nuevo futuro, en los que la degradación del espacio se nos muestra como un devenir propio de grandes ciudades. Aparentemente visibles, abiertos al transeúnte, en los que se agolpan descampados, chabolas, malezas, casas bajas, paneles comerciales,..., marcando unos espacios marginales que esquivan el control (figura $\mathrm{n}^{\circ} 20$ ).

Marcando las distancias entre áreas residenciales y empresariales, y, la propia estación de Chamartín y las oficinas de Adif, surgen "holey places" producto de los espacios huecos, vacíos, originados por el muro de contención que sirve de separación de usos del suelo - con objeto de aislar y contener los llamados "junkspaces" (ver figura $\mathrm{n}^{\circ} 21$ ). Dichos espacios marcan el camino de torres de alta tensión, marcando una clara diferenciación de paisajes urbanos.

El conjunto de lo que se viene a denominar "espacios basura interiores o junkspaces", que conforman las proximidades de la red ferroviaria de Chamartín, cobran una notable expresión paisajística, al mostrarse como "puertas abiertas" hacia una realidad de espacios internos, que nos adentran, en apariencia, a lo desconocido. Se constituyen así como lugares banales, controlados, marcados por el "urbanwilds", y que nos dan cuenta de la intencionalidad de generar barreras urbanas (ver figura $\mathrm{n}^{\circ} 22$ ). 


\section{FIGURA n 18 \\ PAISAJES ESPONTÁNEOS EN LA URBE DE MADRID}

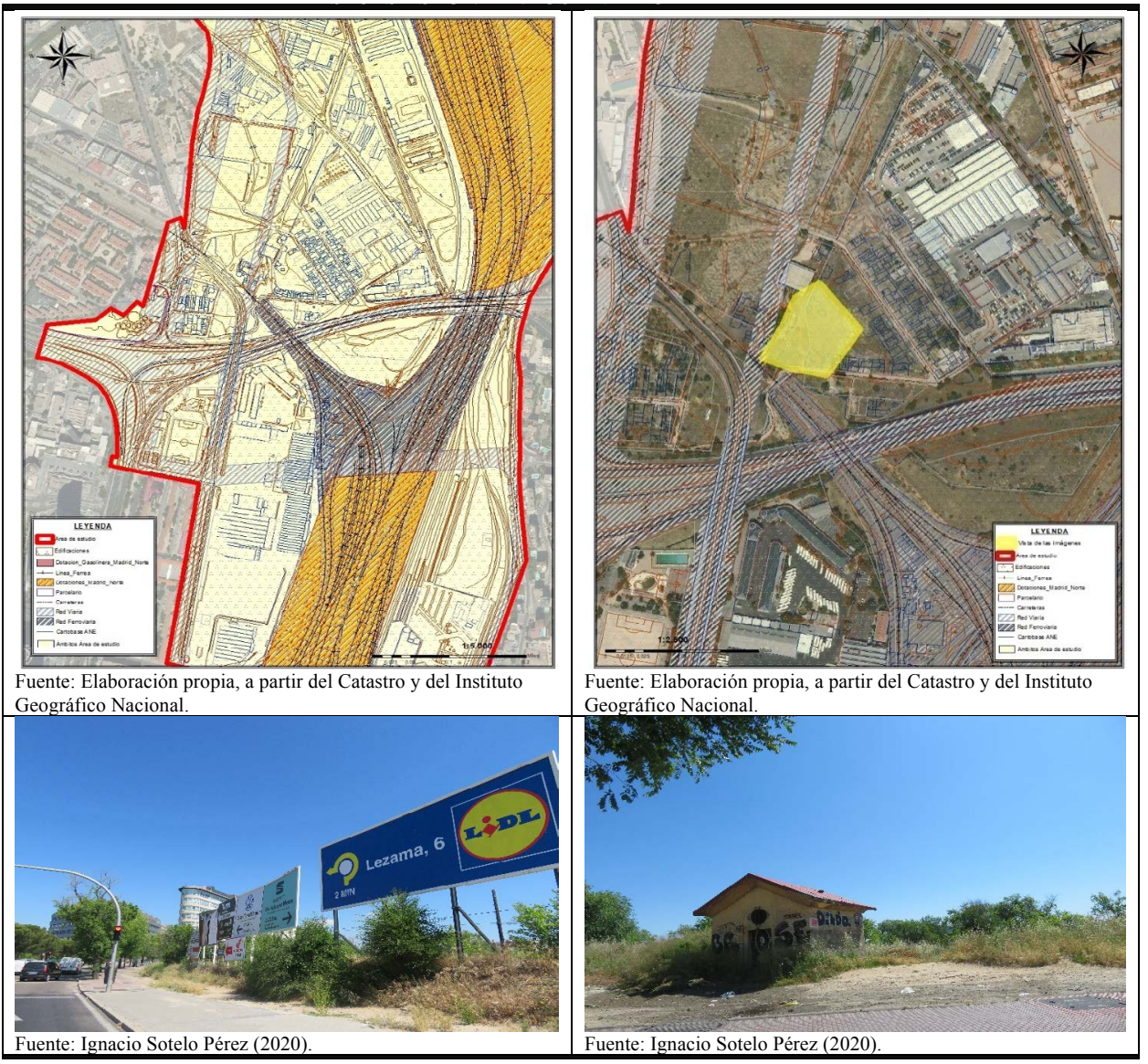

LEgiSlaCión y Ámbitos de ACTUACión

- Modificación del Plan General de Ordenación Urbana de Madrid (1997)

- APE 08.20 Malmea-San Roque-Tres Olivos

Key Performance Indicator (KPI)

- Objetivos: Económicos, Sociales, Ambientales, Regeneración del Paisaje, • Principios: $\quad$ Vertebración. Crecimiento y Desarrollo. Crecimiento, desarrollo, cohesión y competitividad.

- Indicadores: Primera Generación (FPEIR). Tercera Generación (triple dimensión).
- Políticas e Instrumentos: Políticas Finalistas y Específicas (instrumentales y sectoriales). Instr. regulatorios y económicos. 


\section{Figura $\mathbf{n}^{0} 19$}

\section{LUGARES FUERA DE LUGAR EN MADRID NUEVO NORTE}

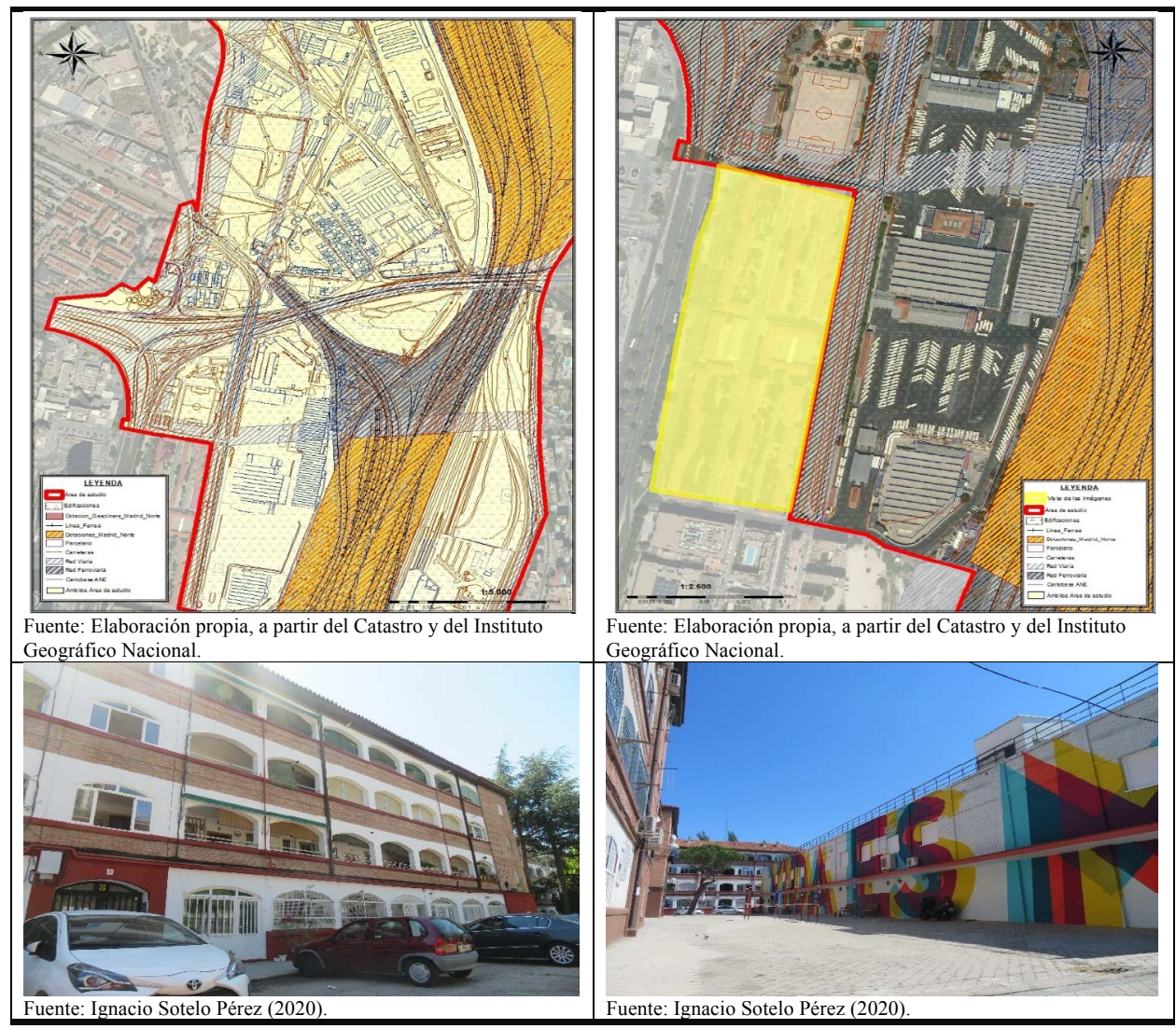

\begin{tabular}{|c|c|}
\hline \multicolumn{2}{|l|}{ LEGISLACIÓN Y ÁMBITOS DE ACTUACIÓN } \\
\hline - Modificación del Plan General de Ordenación Urbana de Madrid (1997) & $\begin{array}{l}\text { - } \text { APE 05.30 Centro de } \\
\text { Negocios Chamartín }\end{array}$ \\
\hline \multicolumn{2}{|l|}{ Key PERformance IndiCATOR (KPI) } \\
\hline - Objetivos: Económicos, Sociales, Ambientales, Crecimiento y Desarrollo. & $\begin{array}{l}\text { - Principios: Accesibilidad y } \\
\text { vertebración. Crecimiento, } \\
\text { desarrollo y cooperación, } \\
\text { Competitividad y Cohesión } \\
\text { territorial. }\end{array}$ \\
\hline - Indicadores: Primera Generación (FPEIR). & - Políticas e Instrumentos: \\
\hline Tercera Generación (triple dimensión). & $\begin{array}{llr}\text { Políticas } & \text { Finalistas y } \\
\text { Específicas } & \text { (instrumentales }\end{array}$ \\
\hline & $\begin{array}{l}\text { y sectoriales). Instr. } \\
\text { regulatorios y económicos. }\end{array}$ \\
\hline
\end{tabular}




\section{Figura no 20 \\ MADRID NUEVO NORTE Y SUS SHADOWED PLACES}

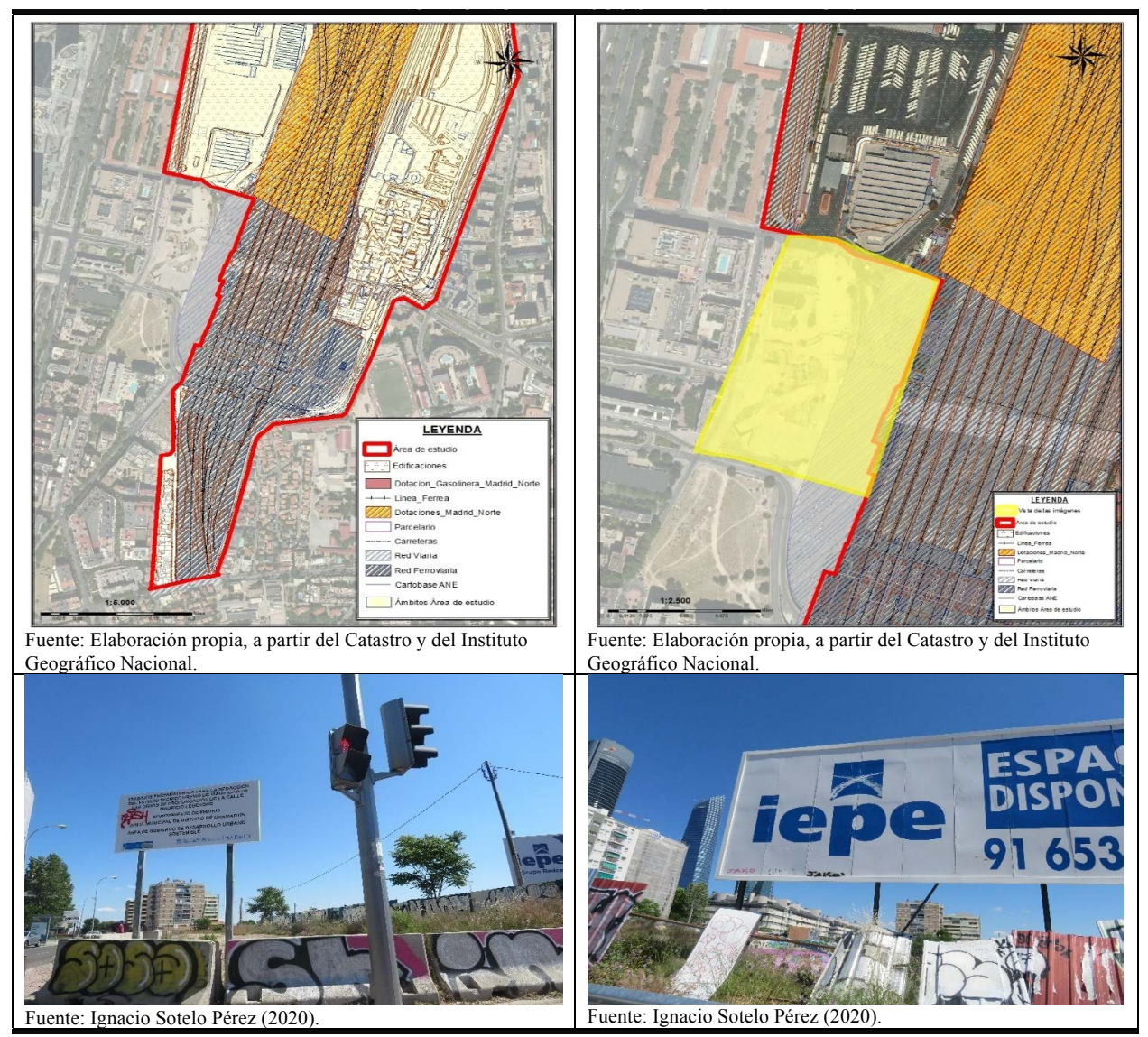

Sotelo Perez $(2020)$

Fuente: Ignacio Sotelo Pérez (2020)

Fuente: Elaboración propia, a partir del Catastro y del Instituto Geográfico Nacional
- Modificación del Plan General de Ordenación Urbana de Madrid (1997)

Key Performance Indicator (KPI)

- Objetivos: Económicos, Tecnológicos, Ambientales, Sociales, Regeneración del paisaje, Crecimiento y Desarrollo.

- Indicadores: Primera Generación (FPEIR). Tercera Generación (triple dimensión).
- APE 05.30 Centro de Negocios Chamartín

- Principios: Accesibilidad y vertebración. Crecimiento, desarrollo y cooperación, Competitividad y Cohesión territorial.

- Políticas e Instrumentos: Políticas Finalistas y Específicas (instrumentales y sectoriales). Instr. regulatorios y económicos. 
FIGURA n 21

\section{EL URBAN WILD DE MADRID NUEVO NORTE}

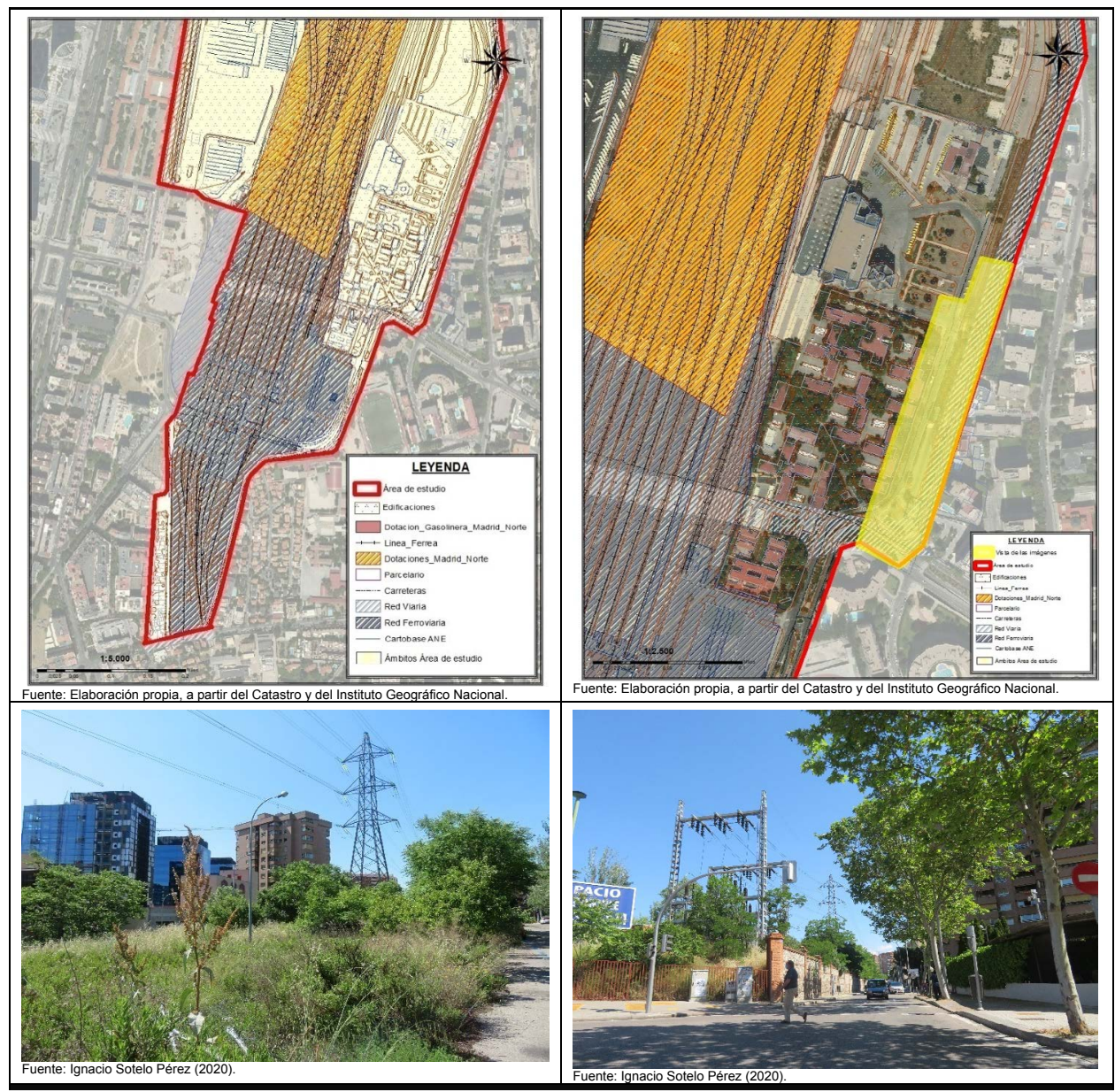

Legislación y Ámbitos de ACTUACión

- Modificación del Plan General de Ordenación Urbana de Madrid • APR 05.10 Estación de (1997) Chamartín.

Key Performance Indicator (KPI)

- Objetivos: Económicos, Tecnológicos, Ambientales y • Principios: Accesibilidad y Regeneración del paisaje.

- Indicadores: Primera Generación (FPEIR). Tercera Generación (triple dimensión). vertebración. Crecimiento, desarrollo y cooperación, Competitividad y Cohesión territorial.

- Políticas e Instrumentos: Políticas Finalistas y Específicas (instrumentales $\mathrm{y}$ sectoriales). Instr. regulatorios $\mathrm{y}$ económicos. 


\section{Figura no 22 \\ CAMINANDO A LO DESCONOCIDO: ENTRE MUROS Y ESTACIONES DE METRO}

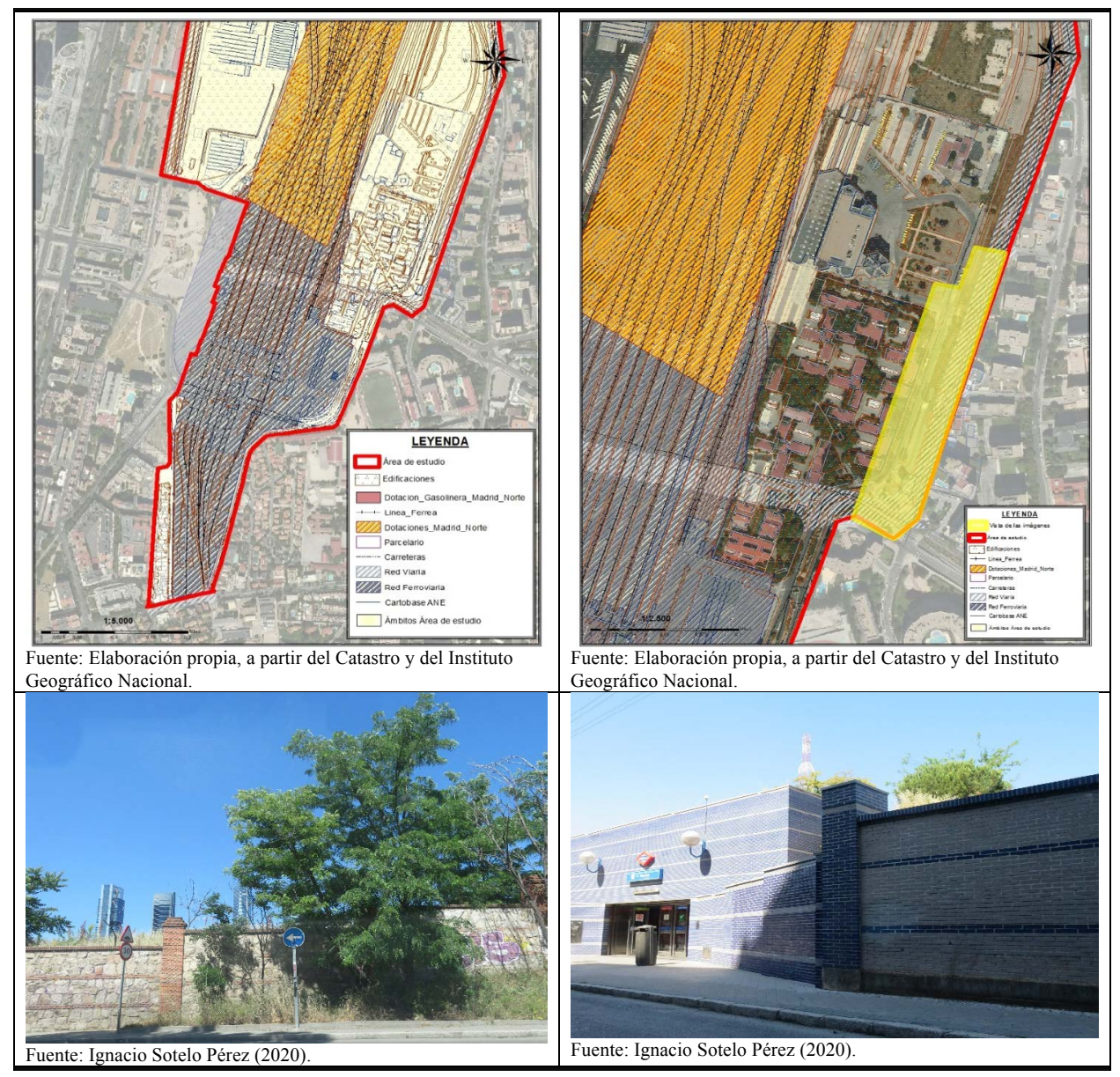

\begin{tabular}{|c|c|}
\hline \multicolumn{2}{|c|}{ LEgISLACión y ÁmBitos de ACTUACIÓn } \\
\hline $\begin{array}{l}\text { - Modificación del Plan General de Ordenación Urbana de Madr } \\
\text { (1997) }\end{array}$ & \begin{tabular}{l|l} 
rid & APR 05.10 Estación de \\
Chamartín.
\end{tabular} \\
\hline \multicolumn{2}{|c|}{ KEy PERFORMANCE INDICATOR (KPI) } \\
\hline $\begin{array}{l}\text { - Objetivos: Económicos, Tecnológicos, Sociales, Ambientales, • } \\
\text { Crecimiento y Desarrollo. }\end{array}$ & $\begin{array}{l}\text { Principios: Accesibilidad y } \\
\text { vertebración. Crecimiento, desarrollo } \\
\text { y cooperación, Competitividad y } \\
\text { Cohesión territorial. }\end{array}$ \\
\hline - Indicadores: Primera Generación (FPEIR). & Políticas $\quad$ e Instrumentos: \\
\hline Tercera Generación (triple dimensión). & $\begin{array}{l}\text { Políticas Finalistas y Específicas } \\
\text { (instrumentales y sectoriales). Instr. } \\
\text { regulatorios y económicos. }\end{array}$ \\
\hline
\end{tabular}




\section{A MODO DE CONCLUSIONES}

Llegados a este punto podemos concluir, y así queda recogido en la aplicación de nuestra Metodología, que en los terrenos en los que se va a desarrollar el proyecto "Madrid, Nuevo Norte", encontramos una gran cantidad de elementos componentes del Tercer Paisaje (Lostspaces; Non-lieux; Junkspaces; Shadowed Places; Terrainvague; SLOAP; Drosscapes; Spazirifiuto, spaziscoria, spazi-scarto; Tiers Paysage; Hyper-lieux; Non place urban realm. Estos nombres, que se suman a los más genéricos de terrenos baldíos, descampados, vacíos urbanos, suelos vacantes o espacios residuales, van asociados a diferentes lecturas y valoraciones de los lugares que designan, realizadas desde paradigmas diversos-formal, socio-funcional o medioambiental-, y también a diferentes propuestas de estrategias de intervención $-\mathrm{o}$ de no intervención - en los mismos) ${ }^{12}$.

$\mathrm{Y}$ es que, consecuencia de los procesos de expansión de la ciudad de Madrid, surgen espacios divergentes en los que antiguas construcciones primigenias, de una planta, se ven devoradas por edificaciones de mayor altura que se agolpan unos con otros, dejando espacios vacíos a la espera del lucro urbanístico. Lugares cuya estética dan cuenta de la falta de proporcionalidad ante la heterogeneidad del territorio y marcan nuevas jerarquías de poder que dimanan del propio ordenamiento urbanístico.

De hecho, el proceso de valoración del capital inmobiliario circulante, se pone de manifiesto en la presente investigación, requiere el control de una condición externa al mismo: el suelo edificable. No debemos olvidar que en cada ciclo de valoración hay que empezar por "liberar" suelo. La propiedad del mismo en las áreas externas, e incluso en algunas internas, de la ciudad, destinadas a ser ocupada por el crecimiento urbano, presenta al comenzar el proceso, de forma intensa, un carácter patrimonial (quiere esto decir que las transmisiones de propiedad, posiblemente, hasta ese momento se basaban en herencias o en operaciones de compra-venta de suelo rústico; es decir, el tráfico del bien no estaba condicionado, todavía, por las expectativas creadas por la futura utilización urbana). Esta realidad se verá completamente transformada por la incidencia, aún incierta, de la pandemia generada a nivel mundial por la Covid-19.

De ella, dimanarán, directa o indirectamente, nuevas actividades turísticas que pueden ser una de las soluciones a integrar en el proyecto denominado "Madrid, Nuevo Norte". En el territorio sobre el que se desarrollará, no debemos olvidar, encontramos un conjunto de lo que se viene a denominar "espacios basura interiores o junkspaces", que conforman las proximidades de la red ferroviaria de Chamartín, cobran una notable expresión paisajística, al mostrarse como "puertas abiertas" hacia una realidad de espacios internos, que nos adentran, en apariencia, a lo desconocido. Los procesos de reconversión y, por ende, de recalificación de los suelos limítrofes a la estación de Chamartín, nos hacen eco de una constreñida dualidad entre aquellos terrenos que encontraron un nuevo uso y otros que se disiparon entre el asfalto. Terrenos baldíos a la espera de un nuevo futuro, en los que la degradación del espacio se nos muestra como un devenir propio de grandes ciudades, como Madrid.

12 PÉREZ IGUALADA, J. (2018: “Los nombres de los lugares sin nombre!”, ACE: Architecture, Cityand Environment =Arquitectura, Ciudad y Entorno, vol. 13 (38), pp. 129-150. 


\section{BIBLIOGRAFÍA}

ALLENDE, J. (1995): “Desarrollo sostenible. De lo global a lo local”, Ciudad y TerritorioEstudios Territoriales, $\mathrm{n}^{\circ} 104, \mathrm{pp} .267-281$.

ANTON, S. ET AL. (2011): "Mass Tourism Development on the Mediterranean Coast", Tourism Geographies, vol. 13 (3), pp. 495-501.

AYUNTAMIENTO DE MADRID (2015): Estado de la Movilidad de la Ciudad de Madrid (2014), 43 pp.

AYUNTAMIENTO DE MADRID (2018): Inventario de Emisiones de Contaminantes a la Atmósfera en el Municipio de Madrid (1999-2016), 56 pp.

BORREL, M.D. (2005): «Turismo, medioambiente y desarrollo sostenible en el Mediterráneo», Observatorio Medioambiental, nº 8, pp. 305-330.

ALLUN, P. (1995): State and Society in Western Europe. Cambridge, Polity Press.

MUÑOZ, R. (Coord.) (1989): Crisis y futuro del Estado de Bienestar. Madrid, Alianza Universidad.

NAREDO, J.M. (1987): La economía en evolución. Madrid, Siglo XXI.

MARTÍN SIMÓN, J.M. (1983): "El significado de las externalidades", Cuadernos de Economía, vol.11 (32). pP. 405-434.

SOLÁ, J.J (1974): "Por una Estructura Operativa de la Política Económica, Revista Española de Economía, vol. 4 (1), pp. 9-44.

SOTELO NAVALPOTRO, J. (1995): Economía Española: Los Marcos Sectorial y Social. Madrid, Editorial Mapfre, Fundación Mapfre Estudios, Instituto de Ciencias del Seguro, Colección Universitaria, Madrid.

SOTELO PÉREZ, M., SOTELO PÉREZ, I. y SOTELO NAVALPOTRO, J.A. (2019): Observatorio. Medioambiental, $\mathrm{n}^{\circ}$ 22, pp. 91-109.

SOTELO NAVALPOTRO, J.A. y ALGARRA, A.A. (1999): "Política Económica y Medio Ambiente", Observatorio Medioambiental, n 2, pp. 311-330.

SOTELO NAVALPOTRO, J.A. (1998): "Los contextos de la Política Ambiental Española actual: adaptación del Quinto Programa de la U.E.”, Observatorio Medioambiental, $\mathrm{n}^{\circ} 1$, pp. 127-140.

SOTELO NAVALPOTRO, J.A. (1998): "Medio Ambiente y Desarrollo en la España de los noventa: la problemática regional de los residuos tóxicos y peligrosos", Anales de Geografía de la Universidad Complutense de Madrid, $\mathrm{n}^{\circ}$ 18, pp. 257-280.

TAMAMES, R. (1 977): Ecología y Desarrollo. Madrid. Alianza Editoral.

TAMAMES, R. (1989): "Pobreza, penuria y subdesarrollo", Documentación Social, no 76. pp. 33-41.

VERA REBOLLO, J.F. e IVARS, J. (2009): "Spread of low-cost carriers: tourism and regional policy effects in Spain", Regional Studies, vol. 43 (3), pp. 559-570. 